\title{
HOW DO PROVIDERS RESPOND TO PUBLIC HEALTH INSURANCE EXPANSIONS? EVIDENCE FROM ADULT MEDICAID DENTAL BENEFITS
}

\author{
Thomas C. Buchmueller \\ Sarah Miller \\ Marko Vujicic \\ Working Paper 20053 \\ http://www.nber.org/papers/w20053
NATIONAL BUREAU OF ECONOMIC RESEARCH
1050 Massachusetts Avenue
Cambridge, MA 02138
April 2014

This paper greatly benefited from comments by Jeff Clemens and seminar participants at Cornell University Policy Analysis and Management, University of Michigan, Indiana University and Case Western Reserve University. The views expressed herein are those of the authors and do not necessarily reflect the views of the American Dental Association or the National Bureau of Economic Research.

NBER working papers are circulated for discussion and comment purposes. They have not been peerreviewed or been subject to the review by the NBER Board of Directors that accompanies official NBER publications.

(C) 2014 by Thomas C. Buchmueller, Sarah Miller, and Marko Vujicic. All rights reserved. Short sections of text, not to exceed two paragraphs, may be quoted without explicit permission provided that full credit, including $(\mathcal{C}$ notice, is given to the source. 
How Do Providers Respond to Public Health Insurance Expansions? Evidence from Adult Medicaid Dental Benefits

Thomas C. Buchmueller, Sarah Miller, and Marko Vujicic

NBER Working Paper No. 20053

April 2014

JEL No. I11,I13,I18

\begin{abstract}
A large and growing number of adults are covered by public insurance, and the Affordable Care Act is predicted to dramatically increase public coverage over the next several years. This study evaluates how such large increases in public coverage affect provider behavior and patient wait times by analyzing a common type of primary care: dental services. We find that when states add dental benefit to adult Medicaid coverage, dentists' participation in Medicaid increases and dentists see more publicly insured patients without decreasing the number of visits provided to privately insured patients. Dentists increase the total number of visits they supply each week while only modestly increasing the amount of time they spend working. They achieve this primarily by making greater use of dental hygienists. As a result, dentists' income increases. Wait times increase modestly, with the largest increases in wait times observed in states with restrictive scope of practice laws governing dental hygienists. These changes are most pronounced among dentists who practice in poor areas where Medicaid coverage is greatest.
\end{abstract}

Thomas C. Buchmueller

Stephen M. Ross School of Business

University of Michigan

701 Tappan

Ann Arbor, MI 48109

and NBER

tbuch@umich.edu

Sarah Miller

Department of Economics

University of Notre Dame

Notre Dame, IN 46556

smille33@nd.edu
Marko Vujicic

American Dental Association

211 East Chicago Avenue

Chicago, IL 60611

vujicicm@ada.org 


\section{Introduction}

The number of non-elderly, non-disabled adults enrolled in Medicaid has grown three-fold since the 1970s, from approximately 4.5 million in 1975 to 15 million in 2010 (Centers for Medicare and Medicaid Services (2013)). As a result of the Affordable Care Act, this number is expected to almost double by 2015 and roughly 20 million more people are expected to gain private health insurance coverage through the health insurance exchanges (Congressional Budget Office (2013)). However, providing coverage is not equivalent to providing access to services. These coverage expansions will only translate to increased access to health care if there is adequate provider capacity to meet the new demand. Some analysts and policymakers have expressed concern that not only will access be a problem for the newly covered, but also that these coverage expansions might generate significant negative "spillover" effects for those who are already insured, increasing wait times and reducing access to care. This concern is especially acute for primary and preventive care, as over 57 million Americans live in areas that are deemed by the Centers for Medicare and Medicaid Services to be "primary care health professional shortage areas" (U.S. Department of Health and Human Services (2013)). On the other hand, providers may be able to adjust the amount or type of care they provide in response to public health insurance expansions in ways that can mitigate these negative spillovers.

Understanding how health care professionals respond to increases in public health insurance coverage is critical for evaluating the costs, benefits, and incidence of such expansions. However, despite its importance, relatively little is known on this topic. In this paper, we investigate how providers respond to public health insurance expansions by studying several large increases and decreases in Medicaid coverage for an important and common type of primary care: dental services. Although states are required to provide dental benefits for children who are publicly insured, Medicaid dental coverage for adults is optional. As a result, many states do not cover dental services at all for adults and several states have added or dropped adult dental benefits over the last decade.

Using the variation in population coverage caused by these policy changes, we test for the effect of Medicaid coverage on several supply-side outcomes: dentist participation in 
the program; the amount of services provided to patients with different insurance coverage; the labor supply of dentists; the employment and use of dental hygienists; dentists' income; and patient wait times. We find that when states expand Medicaid dental coverage for adults, there is an increase in the percentage of dentists that participate in the program and an increase in the supply of services to publicly insured patients, with no decrease in the number of visits for other patients. Dentists accomplish this mainly by making greater use of hygienists: following the expansion of public coverage, dentists employ a greater number of hygienists and hygienists provide about 5 additional visits per week. As a result, dentists' income increases following the adoption of Medicaid adult dental benefits by approximately 7 percent. These effects are largest among dentists who practice in poor areas where Medicaid coverage is most prevalent. We also find that these coverage expansions cause wait times to increase modestly. However, this effect varies significantly across states with different policies towards the provision of dental services by hygienists. The increased wait times are concentrated in states with relatively restrictive scope of practice laws. We find no significant increase in wait times in states that allow hygienists greater autonomy.

The decision to add or drop Medicaid dental coverage may be influenced by a state's budget situation, which will be affected by economic conditions in a state. We conduct several tests to confirm that our results represent the causal effect of the policy change and not the result of economic shocks that may have affected the demand for dental care. First, our point estimates are insensitive to whether or not we condition on time-varying economic variables: gross state product and county-level measures of unemployment and poverty. Second, we conduct two different placebo tests. The first exploits the fact that for each state that changed its Medicaid dental policy during the period of our analysis there is a neighboring state that did not change its policy. When we replace our "changer" states with these neighboring control state, the placebo policy effects are generally insignificant. We get similar results when we replace the changer states with other states that are close statistical matches rather than geographic neighbors. This specification also yields null results, suggesting that the estimates from our main specification are not merely picking up the effect of economic shocks. 
We also perform a permutation test by randomly assigning Medicaid dental policies to states whose policies did not change as an alternative means of conducting inference. The results estimated in states with a true change in dental policy are large relative to the simulated effects, and in many cases exceed all of the simulations. This permutation test confirms that the changes in provider behavior we observe when states add or drop Medicaid dental policies are quite unusual and validate the inference we conduct throughout the paper.

Overall, our results indicate that even large coverage expansions result in only modest negative spillovers in the form of wait times. Dentists are largely able to meet the increased demand by changing the way they practice and by making greater use of dental hygienists. Furthermore, liberal practice laws governing the provision of services by dental hygienists appear to be an important policy factor that keeps wait times low even as coverage expands.

\section{Background and Previous Literature}

\subsection{Previous Research: Coverage Expansions}

A large and growing literature finds that expanding public health insurance coverage increases the utilization of health services. The recent Oregon Health Insurance Experiment provides compelling evidence of a positive effect of coverage on the use of primary and preventive services (Finkelstein et al. (2012)). These experimental results confirm other analyses that use quasi-experimental methods. Several studies find that the Medicaid expansions of the 1980s targeted at children increased their utilization of health services (Currie and Gruber (1996), Aizer (2007), Card and Shore-Sheppard (2004)). Card et al. (2007) find that utilization increases when seniors become eligible for Medicare coverage at age 65. Kolstad and Kowalski (2012) and Miller (2012) find that the expansion of insurance coverage through a state-level health policy reform in Massachusetts increased office visits and preventive care.

In these studies and many others in the health economics and health services literature, ${ }^{1}$ the patient is the unit of analysis and the results can be interpreted as reflecting mainly

\footnotetext{
${ }^{1}$ See Buchmueller et al. (2005) for a review.
} 
demand-side effects. As such, these studies provide no information on how providers respond to the increased demand arising from an expansion of coverage or the extent to which coverage expansions lead to crowding, which affects access for previously insured patients. Since many of these studies focus on relatively small increases in public health insurance coverage (e.g., the Oregon Health Insurance Experiment studied an increase in coverage of only 9,000 individuals), they are of limited value in evaluating the aggregate impact of large coverage increases.

A much smaller literature investigates the impact of public health insurance expansions on provider behavior. Baker and Royalty (2000) examine the impact of Medicaid eligibility expansions for pregnant women on the percentage of a physician's patients who are poor or on Medicaid. They find positive effects on both outcomes for physicians practicing in public health clinics, but not for physicians in private practice. Garthwaite (2012) finds that the expansion of public health eligibility of children through the State Children's Health Insurance Program (SCHIP) increased the probability that a pediatrician would accept public insurance, but was associated with a decrease in the average number of hours worked. This latter result is surprising, given the strong evidence that increases in public insurance coverage lead to increased utilization of care. One possible explanation is that for the physicians in Garthwaite's sample, the main effect of SCHIP was to shift children from private insurance to public insurance, with little change in the overall demand for care. Another possibility is that SCHIP did lead to a net increase in insurance coverage but the resulting increase in demand for services was met by other providers, such as nurse practitioners or physicians assistants.

Both of these papers have relatively limited data about the supply of services and no direct information on crowding. For example, neither study provides information on employment practices, use of other health professionals (such as nurses or physicians assistants), care to patients who are not publicly insured, or wait times. We examine all of these outcomes. There are two other important differences between our analysis and the studies by Baker and Royalty (2000) and Garthwaite (2012). One concerns the population affected by the changes in insurance coverage. The coverage expansions they study affected pregnant women 
and children, whereas our analysis focuses on changes in Medicaid coverage for all Medicaideligible adults, a population more closely resembling the group gaining Medicaid eligibility from the Affordable Care Act. The second difference is that our analysis focuses on dentists rather than physicians. As we describe below, the market for dental care shares many important features with the market for primary health care. Thus, evidence on how dentists respond to insurance coverage expansions has implications for primary care providers more generally.

\subsection{Background on Dental Care}

Dental care is one of the most common types of primary care that non-elderly adults receive. Figure 1 compares utilization rates for visits to primary-care physicians, ${ }^{2}$ dentists, dental hygienists, and nurse practitioners using data from the 2010 Medical Expenditure Panel Survey (MEPS). In this survey, 38 percent of adults reported having a dentist office visit in the last year. This is similar to the 39 percent who reported having a visit with a primarycare physician. About 8 percent had a visit with a nurse practitioner, significantly less than the 19 percent who reported a visit with a dental hygienist, although patients often see both dental hygienists and dentists during the same visit. Among those with some utilization in each category, survey respondents report having a similar number of primary care and dental visits, about 2 , in the last year.

A similar percentage of total spending on dental care was paid for by private insurance as compared to other types of health care (43.1 percent for dental care vs. 40.1 for other types of care), although the percent of dental expenses covered by public insurance is much lower (9.4 percent vs 45.7 percent) and the percent of dental expenses paid out of pocket is higher (47.5 percent vs 14.2 percent). The Medicaid program covers 5.8 percent of all dental expenditures and 10.4 percent of other health care expenditures. Although the percentages of adults receiving any care is similar for dental and primary medical care, because fewer people have extremely high spending on dental care, it accounts for a smaller share of total

\footnotetext{
${ }^{2}$ Primary care physicians are defined as physicians who specialize in general practice, family medicine, or pediatrics.
} 
health spending (6.3 percent vs. 14 percent for primary medical care).

As with primary medical care, it is believed that regular dental care prevents more serious conditions and more costly care, such as treatment in a hospital emergency department (ED). Since 2001, ED visits for dental conditions have increased more rapidly than overall ED visits (Wall and Nasseh (2013), Lee et al. (2012)). This increase in ED visits for dental conditions has been attributed to a reduction in access to primary dental care (Wallace et al. (2011), Cohen et al. (2002)). Dental hygiene also has ramifications for adult health beyond oral health. Several studies suggest that poor dental hygiene causes bacteria infection and inflammation, resulting in worse cardio-vascular health, increase incidence of respiratory illness, and adverse pregnancy outcomes such as low birthweight (e.g., De Oliveira et al. (2010), Thoden van Velzen et al. (1984), Beck et al. (1996)).

One way in which preventive dental care is administered is through dental hygienists. Hygienists are trained to provide many of the most common oral health procedures. In all states, dental hygienists may perform prophylaxis (teeth cleaning), apply topical anesthesia, administer x-rays, and provide fluoride treatments, root planing, and sealants. In some states, dental hygienists may also remove or place sutures or perio dressings and diagnose dental hygiene related diseases. There is also variation across states in the level of supervision that is required when dental hygienists perform these services. For example, in Colorado, dental hygienists may open independent practices to perform routine preventive care without the supervision of a dentist, while in Georgia, a dentist must provide direct supervision while a hygienist is rendering services (Academy of General Dentistry (2010)). Even though there are a wide range of tasks that dental hygienists are authorized to do, many dentists do not employ a hygienist and instead provide this care themselves. In our sample, about 67 percent of dentists employ a hygienist.

Concerns over dental shortages have grown in recent years. The Department of Health and Human Services have identified geographic areas and population groups experiencing dental shortages (U.S. Department of Health and Human Services (2013)). The affected population totals over 45 million, similar to the 57 million reported to be in primary care health professional shortage areas. In the US, there are about 7 dentists for every 10,000 
residents, the same as the per capita number of primary care physicians. ${ }^{3}$

Public coverage for dental services is expected to increase as a result of the Affordable Care Act. About 8 million adults are projected to gain dental benefits through the Medicaid program, a little under half of whom will receive "full" dental benefits covering all major preventive and restorative treatments (Yarbrough et al. (2013)). Additionally, dental coverage may increase if the uninsured purchase optional dental insurance through the health care exchanges. The effect of Medicaid coverage on crowding and dentist labor supply is therefore of immediate relevance to evaluate the ongoing public health insurance coverage expansions.

\subsection{Medicaid Dental Coverage}

State Medicaid programs are required to provide dental coverage for children, but not for adults. As a result, there is variation in whether or not states provide any dental benefits for adults and, among states that do provide such benefits, there is variation in what and who is covered. Some states cover only emergency dental services or cover only certain Medicaid enrollees (e.g., pregnant women), while other states provide "full" dental benefits in the sense that they cover a broad range of dental services, including diagnostic and preventive treatments, to all adult enrollees. In our main analysis, we focus on changes in provider behavior resulting from states adding or dropping full dental benefits. That is, we group states that cover a limited set of emergency procedures with those that cover no dental procedures at all. Among our robustness checks, we evaluate how other types of coverage changes affect dentists' behavior and wait times. In general, the effects of providing emergency or partial dental benefits are small.

Table 1 and Figure 2 describe Medicaid dental policies by state. Most states never provide full dental benefits to adult Medicaid recipients over the period we study (1999-2011). These states are listed in the first panel of Table 1. A smaller number of states, listed in the second

\footnotetext{
${ }^{3}$ See http://www.ahrq.gov/research/findings/factsheets/primary/pcwork1/index.html for more details on the primary care physician workforce.
} 
panel of Table 1, always provide adult Medicaid recipients dental coverage over our sample period. The lower panels present states whose Medicaid policy changed over our sample period. Three states added, 6 states dropped, and 3 states both added and dropped full dental coverage for adult Medicaid beneficiaries. ${ }^{4}$ As a result, approximately 2.5 million adult Medicaid beneficiaries gained dental coverage and 8 million lost dental coverage over this period. States without full dental coverage are displayed as white in each of the four maps included in the figure $(1999,2003,2008,2011)$; those that provide full dental coverage are shown in dark gray in each of the four maps. Overall, the number of states providing adult Medicaid enrollees with full dental coverage fell from 15 in 1999 to 10 in 2011, with the latter number including 2 states (Alaska and South Dakota) that did not have dental coverage in 1999.

As with primary medical care, there is a long-standing concern that low Medicaid reimbursement rates limit the number of dentists that accept publicly insured patients, leading to access problems. According to a survey of state Medicaid programs conducted by the U.S. General Accounting Office (2000), in most state fewer than half of all dentists accept Medicaid patients. In our data, 39 percent of dentists report treating publicly insured patients (see Table 2). Even with this low rate of provider participation, there is substantial evidence that Medicaid coverage increases access to dental care. Three recent studies have demonstrated that adding dental benefits to Medicaid substantially increases the demand for dental services among adult enrollees (Choi (2011), Nasseh and Vujicic (2013), Brodsky (2013)). These estimated effects imply that changes in Medicaid coverage policy will translate to potentially large demand shocks for a typical dentist. On average, dentists in our sample practice in a county where about 9 percent of adults are Medicaid beneficiaries. The provision of dental benefits to Medicaid recipients may therefore represent an increase in demand for the average dentist that is large enough to have a meaningful impact on his or her behavior. These changes are also large enough that they may plausibly lead to crowding and result in longer wait times.

\footnotetext{
${ }^{4}$ We also conduct analysis using only states that add, but not that drop, adult Medicaid dental benefits. We find qualitatively similar results, but because this approach relies on us drastically reducing our sample, the confidence intervals are large.
} 


\subsection{A Model of Provider Behavior}

A useful theoretical framework for analyzing provider responses to public insurance expansions is a model by Sloan et al. (1978), which assumes that providers face a downward sloping demand curve for private patients and a fixed unit price for treating Medicaid patients. As illustrated in Figure 3, this combination produces a kinked marginal revenue curve. At low levels of output, providers will treat only private patients for whom the marginal revenue curve slopes down. When that curve equals the fixed Medicaid price, that price becomes the relevant marginal revenue. If there is a limit to the number of publicly insured patients in the market, at some level of output the marginal revenue curve may become downward sloping again.

Providers are assumed to choose a quantity of output such that marginal revenue equals marginal cost. Therefore, the mix of public and private patients treated depends on where the marginal cost curve falls relative to this kinked marginal revenue curve. For a provider with a high marginal cost or a strong private demand-illustrated by the marginal cost curve $M C_{1}$-the point of intersection will be on the downward-sloping portion of the curve and only private patients will be seen. In contrast, a provider with a marginal cost curve like $M C_{2}$ will see a mix of public and private patients, with the total number of patients determined by the intersection of the marginal cost curve and the Medicaid price. A provider with marginal cost like $M C_{3 a}$ or $M C_{3 b}$ will also see a mix of public and private patients, but because there is a limit to the number of publicly insured patients in the market, the marginal patient will be a private patient.

This model predicts that the response of dentists to a public insurance expansion will depend on the mix of patients they are seeing before the expansion and the extent to which the increase in public coverage represents an overall gain in coverage-i.e., the extent of crowd-out. When crowd-out is minimal, an expansion of public insurance can be seen as an extension of the horizontal portion of the marginal revenue curve. Such a change will have no effect on providers like those represented by $M C_{1}$ and $M C_{2}$ because it does not change the point where their marginal cost and marginal revenue curves intersect. On the other hand, for a provider with a marginal cost like $M C_{3 a}$ or $M C_{3 b}$, an expansion of public insurance 
represents an increase in marginal revenue that should lead to an increase in public patients treated.

Providers who initially see the same mix of public and private may vary in their response to an expansion of public insurance depending on the shape of their marginal cost curve, which may depend on state scope of practice regulations. The most restrictive scope of practice laws, which require hygienists to be directly supervised by dentists, essentially imposes a Leontief production function, in which dentists and hygienists are perfect complements. ${ }^{5}$ In such a case increasing output requires increasing both labor inputs. If the supply of dentists' time is very inelastic in the short run, the marginal cost function will also be inelastic, such as $M C_{3 a}$. In contrast, regulations that allow hygienists to have more professional autonomy make it easier for dental practices to substitute one type of labor for another. For example, when hygienists can provide more services without supervision by a dentist, a practice can schedule visits with dentists and visits with hygienists independently. This will increase the productivity of the practice and result in a more elastic supply curve, similar to $M C_{3 b}$. Thus, we would expect that dentists practicing in states with more flexible scope of practice laws will be better able to increase supply in response to a demand shock than dentists in states with more restrictive regulations.

\section{$3 \quad$ Data and Empirical Strategy}

\subsection{The Survey of Dental Practices}

Our analysis is based on 13 years of data (1999 to 2011) from the Survey of Dental Practices (SDP), a nationally representative random sample of dentists in private practice ${ }^{6}$ conducted by the American Dental Association (ADA) Health Policy Resources Center. The survey provides information on participation in Medicaid, weekly visits, hours worked, income, employment practices, and average wait times for about 3,000 dental practices each year.

\footnotetext{
${ }^{5}$ See Marier and Wing (2014) for a more complete discussion of how scope of practice laws affect the production function of a health care practice.

${ }^{6}$ The ADA estimates that about 92 percent of active dentists in the United States are in private practice.
} 
With one exception, the outcomes we analyze are measured directly in the survey. That exception is the number of visits by insurance status, which we construct by multiplying the percent of patients falling into each insurance category by the total number of visits per week. We then scale this by the ratio of the average number of visits reported per week for patients in each insurance category using data from the Survey of Income and Program Participation. There may be some mis-measurement in this variable, if, e.g., newly-publicly insured patients visits the dentist more frequently than a typical publicly-insured patient. To account for this, we also present models that evaluate the total number of visits (not categorized by insurance status) and the percent of patients in each insurance category separately.

The survey provides information on several dentist and practice characteristics that we use as controls: whether the respondent dentist is a general practitioner, whether she is an owner of the practice, how long she has been practicing and the number of dentists in the practice. We also observe the zip code of each practice, which allows us not only to match dental practices to state policies but also to control for local area (county- and state-level) economic and demographic factors. At the county level, we control for the unemployment rate, the percent of the population that is black, the percent of the population that is under 18, and the poverty rate; at the state level, we control for the gross state product and the uninsurance rate. Table 2 provides summary statistics on the outcome variables and these controls. Because response rates vary across questions, we report the sample size for each variable in the third column.

To measure states' provision of dental benefits, we match the SDP to information on Medicaid dental coverage by year. State Medicaid programs can be classified as providing "full," "limited," or "emergency" coverage or no coverage at all. If states only cover a subset of adult Medicaid recipients, or if they fail to cover common dental procedures, their dental coverage is classified as limited. If states cover only dental services in the case of a dental emergency, their coverage is classified as emergency. In our main analysis, we restrict our evaluation to the provision of full coverage of dental benefits. In a later section, we discuss alternative specifications where we estimate the effect of emergency and limited coverage on 
dentists' behavior.

\subsection{Empirical Strategy}

Our main empirical specification is a reduced form model that uses state and year fixed effects to identify the effect of Medicaid policy on dentists' labor supply and other outcomes. Specifically, we estimate

$$
Y_{i s t}=\beta_{s}+\beta_{t}+\beta_{1} F_{u l l}+\beta_{2} X_{i}+\beta_{3} Z_{i}+\epsilon_{i s t}
$$

In this model, the state fixed effects $\left(\beta_{s}\right)$ control for any state characteristics that are invariant over time, the year fixed effects $\left(\beta_{t}\right)$ control for any changes in behavior that are common to providers in all states. The variables $X_{i}$ and $Z_{i}$ are the practice- and area-level controls described in the previous section. The regressor of primary interest is Full, an indicator variable that equals 1 for states that provide full adult dental coverage in their Medicaid program and 0 for states that do not. Although a substantial amount of variation comes from states dropping, rather than adding, dental coverage (see Table 1), the coefficient $\beta_{1}$ represents the effect of an increase in dental coverage rather than a drop in coverage. We estimate standard errors clustered at the state level to account for serial correlation within states (see Bertrand et al. (2004)).

Previous research, including a recent study using data from the SDP, finds that the willingness of dentists to treat Medicaid patients is positively related to the level of Medicaid payment rates (Buchmueller et al. (2013), Decker (2011)). We have data on Medicaid rates for some, but not for all of the sample. In particular, for several states, we do not have data

prior to 2001. Including Medicaid payment rates as an explanatory variable (and reducing the sample accordingly) does not materially affect our main results. Therefore, so that we can use data from all years, we focus mainly on models that do not condition on Medicaid payment rates.

We also estimate a slightly different specification that relates the same outcome variables 
to the extent of Medicaid dental coverage in a local area:

$$
Y_{i s t}=\gamma_{s}+\gamma_{t}+\gamma_{1} \text { PercentMedicaid }{ }_{c t}+\gamma_{2} X_{i}+\gamma_{3} Z_{i}+\epsilon_{i s t}
$$

This model includes the same covariates as (1) but replaces the indicator for full Medicaid coverage with the percentage of the adult population in a dentist's county that has Medicaid dental coverage. We construct this variable using county-level data from the American Community Survey and information on state Medicaid policy captured by the variable $F u l l_{s t}{ }^{7}$

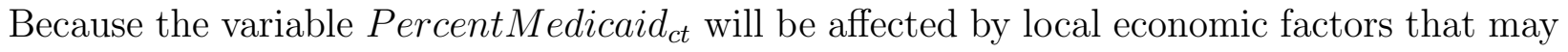
have a direct effect on the demand for dental care, it is an endogenous regressor. Therefore, we instrument for it using the indicator $F u l l_{s t}$ that varies by state and year. Note that since the identifying variation is the same in both specifications, the only difference is one of scaling and interpretation. The reduced form estimates (1) represent dentists' response to the discrete change in demand that occurs when states go from not covering dental care for adults to covering dental care, whereas in (2) the coefficient $\gamma_{1}$ represents the effect of an incremental change in Medicaid coverage. The reduced form model captures more directly the variation that provides our identification, while the IV results may be more useful for thinking about provider responses to incremental coverage expansions, like those of the Affordable Care Act. For the sake of brevity, we report only the results from the reduced form models, though we refer to the IV results in the text to provide context for and interpretation of the reduced form estimates.

Both models assume that any change in provider behavior that is observed when states add dental benefits is due to the change in the state Medicaid policy rather than an unrelated contemporaneous change in the practice environment. Given the period that we study, it is particularly important to adequately control for macroeconomic shocks that may have both affected state policy and had an independent effect on the demand for dental services. Although we cannot directly test the exogeneity of our main policy variable, we take several steps to assess the internal validity of our approach. First, we control for potential

\footnotetext{
${ }^{7}$ Because the American Community Survey did not collect information on insurance status prior to 2008, for 1999 to 2007 we use state-level Medicaid enrollment and the observed 2008-2011 ratio of state to county Medicaid enrollment to generate estimates of county-level adult Medicaid coverage. We describe this procedure in greater detail in the appendix.
} 
confounders related to the overall economic environment of the county in which the dentist practices. Comparing results from models that do and do not include these controls provides some sense of how sensitive our results are to state-specific economic shocks. Second, we conduct two different types of placebo tests. The first uses neighboring states that did not experience changes in Medicaid dental coverage policy. The second replaces states experiencing a change in policy with states that are close matches in terms of economic conditions over the period of our analysis. Finally, we evaluate the quality of our inference by performing permutation tests that randomly assign Medicaid dental policies to states that did not experience a change. All of these methods strongly suggest that the observed changes in dental practices are driven by the change in Medicaid policy.

\section{Main Results}

\subsection{Participation}

If expanding Medicaid coverage does not increase the amount of publicly insured patients that a dentist sees, we should not expect effects on other aspects of that dentist's practice. It is therefore necessary to observe changes in Medicaid participation in order to determine if other changes in dentist behavior are plausibly caused by changes in Medicaid policy. We measure a dentist's Medicaid participation in three ways. First, we analyze the extensive margin of participation, using an indicator variable equal to 1 if a dentist treats any publicly insured patients and 0 otherwise. For this outcome, we use a linear probability, though the results are similar when we use a logit model. Second, we analyze the percent of a dentist's patients who are publicly insured. Third, we use information from a separate question on the fraction of gross receipts that a dentist receives from the government.

The results, which are presented in Table 3, are consistent with prior studies that find a positive relationship between public insurance coverage expansions and program participa-

tion among providers (Baker and Royalty (2000), Garthwaite (2012)). We find that adding full Medicaid benefits increases the probability that a dentist has any publicly-insured pa- 
tients by between 5 and 6 percentage points. Because about 40 percent of dentists in our dataset see publicly insured patients, this represents an increase of about 15 percent. Using the variable Full $_{s t}$ as an instrument for the percentage of adults in the county with Medicaid dental coverage suggests that a 10 percentage point increase in coverage increases the fraction of dentists who see Medicaid patients by about 6.2 percentage points (standard error $(\mathrm{SE})=1.7)$. Medicaid coverage of adult dental care increases the percent of a dentist's patients who are publicly insured by 2.5 percentage points (36 percent). This result implies that a 10 percentage point increase in coverage would increase the average fraction of a dentist's patients who are publicly insured by about 2.6 percentage points ( $\mathrm{SE}=0.9$ ). Covering dental services also significantly increases the percentage of a dentist's receipts that come from the government by 1.8 percentage points and decreases the percent of gross receipts that are paid for out of pocket by between 1.5 and 2 percentage points.

Several of the estimated coefficients on the control variables are statistically significant, with the expected sign. ${ }^{8}$ Dentists with an ownership stake in the practice and dentists who are general practitioners are less likely to have any publicly insured patients. Years of experience is also associated with fewer publicly insured patients, while the number of dentists in a practice is positively associated with seeing publicly insured patients. The poverty rate in the county where a dentist practices is positively associated with the probability that a dentist treats any publicly insured patients and the percentage of patients who have public insurance. Counties with a great proportion of residents under age 18 are also associated with a greater likelihood of treating publicly insured patients, presumably because public insurance for children always covers dental care. However, the coefficient on the indicator for full adult Medicaid coverage is not sensitive to the inclusion or exclusion of these provider and area level controls, providing support for the assumption that changes in adult dental coverage are exogenous in this model.

\footnotetext{
${ }^{8}$ In the appendix, we report and discuss the coefficients on these control variables for selected models.
} 


\section{$4.2 \quad$ Visits}

The effects presented in Table 3 could come from an increase in demand from Medicaid patients, which has potential implications for labor supply and crowding, or they may simply result from patients changing payer status, which would not necessarily imply first order effects on other outcomes. Therefore, it is important to test whether Medicaid dental has a significant effect on the number of visits to a practice.

Table 4 presents results for several measures of dental visits. The first panel presents the change in the total number of visits provided by the dentist per week. We find that adding adult dental benefits to Medicaid causes dentists to provide an additional 2.8 to 3.5 visits per week, an increase of between 4.6 and 5.7 percent. This implies an increase in coverage of 10 percentage point would increase the total number of visits supplied by about $3(\mathrm{SE}=1.7)$ visits per week.

The second panel displays the number of visits per week by the insurance status of the patient. We find no change in the number of visits provided to privately insured patients, but a significant increase in the number of visits for publicly insured patients of about 2 additional visits per week. This result implies that increasing public dental coverage by 10 percentage points would increase the number of visits provided to publicly insured patients by about 2.2 visits $(\mathrm{SE}=0.6)$ per week. We do not observe a reduction in the number of visits to uninsured patients, although our confidence intervals cannot rule out that there was a small reduction in visits supplied to uninsured patients in response to the policy change. These results are consistent with other research that finds that dental visits increase following the adoption of dental benefits by adult Medicaid programs, and suggest that dentists were able to increase care to the newly-publicly insured without reducing the amount of care they provided to other patients.

The third panel of Table 4 displays the effect of expanding Medicaid dental coverage for two types of visits: emergency/walk-in visits with a dentist and visits with a hygienist. Emergency or walk-in visits increase significantly, by about 0.5 visits per week, or 9 percent. The total number of visits with all dental hygienists in the practice also increases substan- 
tially, by between 4.5 and 6.1 visits per week, or between 9 and 12 percent. The magnitude of the results for this outcome and the others in Table 4 are not directly comparable because a dental hygienist in a practice may see the patients of more than one dentist. To make dental hygienist visits comparable to dentist visits, we also estimate the average number of dental hygienist visits per dentist in the practice (i.e., \# of Hygienist Visits / \# of Dentists). We find that the average number of patients a hygienist sees per dentist increases by between 3.8 and 4.2. Even after this adjustment, the observed increase in dental hygienist visits is 9 to 20 percent larger than the increase in visits to the dentist, indicating that making greater use of hygienists is an important part of how dentists meet the new demand created by the Medicaid policy changes.

Finally, we estimate the effect of expanding public health insurance coverage for dental services on the average length of a visit with the dentist, in minutes. Although we do not find a statistically significant effect, the point estimate indicates that average visit length falls by between one tenth of a minute to one minute, suggesting that dentists may also adjust the quality of care or efficiency in response to changes in Medicaid policy.

\subsection{Labor Supply, Employment Practices, and Income}

The results in Table 4 indicate that an important way that health care providers may accommodate the increased demand associated with an expansion of insurance coverage is to make greater use of other health professionals, in this case dental hygienists. Dentists themselves may also work longer hours. Either response should result in an increase in practice income. We present results for these outcomes in Table 5.

The first panel presents the results related to dentists' labor supply. We find that when states extend Medicaid dental benefits to adults, dentists modestly increase the amount of time they spend treating patients by about one-half hour per week, an increase of around 1.5 percent. A ten percentage point increase in dental coverage would therefore increase the amount of time a dentist spends treating patients by 0.6 hours per week $(\mathrm{SE}=0.1)$. We also find an increase in total hours worked per week, although this result is only statistically 
significant in the model that does not include controls for dentist and county characteristics.

The results in the second panel of Table 5 show that when Medicaid covers dental care for adults, dental practices are significantly more likely to employ a hygienist. ${ }^{9}$ The probability of employing any hygienists increases by 3 percentage points and the average number of hygienists increases by about 0.1 . Using our IV model to scale these results implies that a ten percentage point increase in coverage increases the fraction of dentists employing a hygienist by 3 percentage points $(\mathrm{SE}=2)$ and the number of hygienists by $0.2(\mathrm{SE}=0.09)$.

The results in the bottom panel of the table suggest that the expansion of Medicaid coverage has a positive effect on dentists' income. We find that adopting Medicaid dental benefits increases income from practice by between $\$ 15,477$ and $\$ 20,480$ annually. This is an increase in income of between 7 and 9 percent relative to the sample mean. Recall, the average number of visits to the dentist increased by 3.5 visits per week and the average number of visits with a hygienist increased by about 4.5 visits per week. Assuming that dentists and hygienists see patients 50 weeks per year, the total number of visits increased by about $(3.5+4.5) \times 50=400$ visits per year. These observed increases in income therefore suggest that the price of a dentist or hygienist visit was between $\$ 39(\$ 15477 / 400)$ and $\$ 51$ (\$20480/400) per visit on average.

As a check, we also estimate models in which the dependent variable is other income from sources related to dentistry that should be less affected by changes in Medicaid coverage policy, such as research, teaching, and a tertiary practice. We find no significant effect of Medicaid coverage on this outcome.

\subsection{Wait Times}

The results in Table 5 indicate that supply increases in response to increased demand for care caused by an expansion of Medicaid coverage. However, if the supply response is not great enough, there will be excess demand, leading to crowding in the form of longer wait

\footnotetext{
${ }^{9}$ We estimate the probability of employing any hygienist using a linear probability model. Results are similar when we employ a logit model instead.
} 
times for appointments and in the waiting room. In this section, we directly test for the effect of expanded dental coverage on these measures of crowding.

Table 6 presents the estimated effects of expanding Medicaid dental coverage on wait times. These results indicate that there is some crowding, but that these effects are modest. We find that the adoption of Medicaid dental benefits increases the number of days an established patient must wait for an appointment by between 0.6 and 0.7 days. The IV specification suggests that a 10 percentage point increase in coverage would increase wait times by 0.7 days $(\mathrm{SE}=0.4)$. We find a similar increase, 0.4 to 0.6 days, in the number of days a new patient must wait for an appointment, although this estimate is not statistically significant. We also find statistically significant, although small, increases in the amount of time a typical patient waits in the waiting room for his or her dental appointment. These results, presented in the second panel of Table 6, indicate that waiting room time increases by about half a minute for both new and established patients.

\subsection{Placebo and Permutation Tests}

Our analysis suggests that expanding public health insurance coverage has a wide range of effects on how health care providers supply care. The identification of these effects comes from changes in state Medicaid policy, which themselves may be influenced by economic

shocks affecting state fiscal conditions. In particular, several states dropped adult dental coverage around the time of the Great Recession. It is therefore important to test whether our results represent causal effects of these policy changes rather than the effect of economic shocks that are not captured by our control variables. In this section, we conduct several placebo tests to evaluate how likely it would be to detect the effects we observe even if there had been no change in Medicaid policy.

First, we analyze changes in the supply of dental services in states that closely resemble the states that changed their Medicaid dental policy but did not themselves actually implement such a change. We match states both on geography and on state characteristics. In the first placebo test, we assign the Medicaid dental policy of each state that experienced a 
coverage change to a neighboring state that did not. We then estimate our primary model "as if" those neighboring states had implemented changes in Medicaid policy themselves. To give one example, both California and Nevada experienced significant economic downturns when the housing market collapsed. In 2009, California dropped adult dental coverage in its Medicaid program, but since Nevada had not provided dental coverage for adults it could not make the same change. With the exception of Alaska, we were able to match every "changer" state to a neighboring state that did not make a policy change. ${ }^{10}$

Additionally, we conduct this test using placebo states that are similar to change states in terms of observable economic variables: the unemployment rate, the gross state product, and the percent of the population of the state that is uninsured. We remove the means of each of these variables and then rank states based on how close they are to each of the treatment states over the sample period using Euclidean distance. ${ }^{11}$ Because the placebo states are similar (either geographically or based on observables) to the actual states that were treated, they are likely subject to the same economic trends and shocks. If our results are picking up changes in the economic environment that are correlated with Medicaid policy changes (for example, if states drop Medicaid dental benefits when the local economy worsens), we should find similar effects when we conduct our analysis in the placebo states.

These results are reported in Table 7 . The first column presents the results that use the geographic neighbors as placebos. We find no statistically significant effects among the 12 outcomes we consider and the point estimates are small. Column (2) presents the results that use the statistical neighbors as placebos. We find a statistically significant change in

\footnotetext{
${ }^{10}$ The other pairs of neighboring changer/placebo states are: Indiana/Kentucky, Iowa/Missouri, Maine/New Hampshire, Minnesota/Wisconsin, New Mexico/Arizona, DC/Maryland, South Dakota/North Dakota, Massachusetts/Connecticut, Michigan/Ohio, and Washington/Oregon. Because Alaska has no immediate neighbors, we drop it from this analysis. We also drop the 13 states that did implement a change in Medicaid dental policy over the sample period.

${ }^{11}$ This results in the following changer/placebo pairs: California/Texas,Indiana/Wisconsin, Maine/Rhode Island, Iowa/South Carolina, Minnesota/Tennessee, New Mexico/Hawaii, Alaska/Wyoming, DC/Kansas, South Dakota/Montana, Massachusetts/Maryland, Michigan/Arkansas and Washington/Georgia. Distance from state $i$ to state $j$ is calculated as $\sqrt{\left(x_{1 i}-x_{1 j}\right)^{2}+\left(x_{2 i}-x_{2 j}\right)^{2} \ldots+\left(x_{n i}-x_{n j}\right)^{2}}$ where $x_{1}, \ldots, x_{n}$ are the de-meaned characteristics of the states in each year.
} 
total income, but it has the "wrong" sign. Otherwise we find no significant effects. We conclude that there is no evidence of the type of the broad changes in practice behavior that we describe in our results section. This placebo test confirms that it is unlikely that the observed changes in provider behavior reported in this paper are driven by changes in the environment of the state that are concurrent with, but unrelated to, the Medicaid dental coverage expansion.

In addition to these placebo tests based on near neighbors of the treated states, we also conduct a large number of placebo tests designed to evaluate how common it would be to observe a change in dental outcomes even if no change in Medicaid policy occurred. These tests are similar in spirit to the approach described in Abadie et al. (2010) and provide an alternative method with which to conduct inference. We create a distribution of null effects by dropping the 13 states that changed their Medicaid dental policy over our sample period and randomly assigning each of the dental policy histories captured by the Full $l_{s t}$ variable to one of the 37 states whose policy did not change. We then estimate our full specification (equation (1)) using the remaining 37 states, estimating the coefficient from equation (1) as if the dental policy changes had occurred in the randomly assigned states. Because no actual policy changes occurred in these states, we should find a coefficient on the variable $F_{u l l}$ that is close to zero. We repeat this procedure 300 times, resulting in a distribution of placebo coefficients. Histograms of these placebo effects for each of our main outcome variables are displayed in Figure 4, with the dashed lines indicating the 97.5th and 2.5th percentiles, and the vertical line indicating the true effect reported in Tables 3-6.

Our results confirm our original inference and show directly that it is unusual to observe changes in the outcome variables of the magnitude reported in Sections 4.1-4.4. For each outcome with one exception, the "true" effect of the change in Medicaid dental policy is outside the empirical 95 percent confidence interval of the estimated placebo effects. The one result that does not exceed the 97.5th percentile (Any Hygienist Employed) does exceeds the 95th percentile. For several outcomes (any publicly insured, percent of patients publicly insured, percent of gross receipts from government payments, number of emergency visits supplied per week, number of visits supplied per week to publicly insured patients), the true 
effect is considerably larger than all 300 placebo effects. These simulations strongly suggest that results of the magnitude that we report are unlikely to be due to chance.

\subsection{Alternative specifications}

In this section, we describe several alternative specifications that model the role of Medicaid coverage of dental benefits on dentists' behavior. These models provide descriptive evidence on how dentists' behavior adjusts to changes in Medicaid policy and verify that our results are robust to alternative definitions of dental coverage. More information on these models, as well as full results, are reported in the appendix.

First, we examine how limited or emergency dental coverage affects the outcomes we consider. The ADA defines dental coverage as "limited" if some Medicaid beneficiaries receive coverage but others do not (e.g., if dental benefits are only included in the coverage of pregnant women), or if some common categories of dental procedures are not covered. Often these uncovered categories are periodontal and advanced restorative services such as root canals and crowns. The ADA defines dental coverage as "emergency" if only emergency dental services, such as the extraction of a diseased tooth, are covered.

To estimate the effects of these different types of dental coverage, we estimate model (1) for our main outcome variables, but add the binary variables Limited $_{s t}$ and Emergency . $_{\text {. }}$ This model measures the effects of full, limited, and emergency dental coverage relative to providing no dental coverage of any type to adult Medicaid beneficiaries. We find that limited and emergency dental services have statistically significant effects on dentist participation in the Medicaid program, although the effects are smaller than those observed when states add full coverage. Limited dental coverage is associated with a significant increase in the number of visits to publicly insured patients, although the effect is smaller than the effect of full coverage. We find no significant effects of limited or emergency dental coverage on number of hours worked or hygienist employment, and only small increases in income associated with limited coverage. We also do not find any evidence that these less comprehensive forms of dental coverage affect wait times. Overall, we conclude that limited and emergency dental 
benefits have only a small impact on dentists' behavior relatively to full dental benefits. Complete results and further discussion of these specifications is found in Appendix Section A.

Second, we conduct an event history analysis that plots the estimated policy effects relative to the year the policy change occurred. Results for our main outcome variables are reported in Appendix Figure 1. In this figure, as in our regression analysis, changes in Medicaid policy are expressed in terms of adding benefits to adult Medicaid coverage rather than dropping these benefits. Although the figures are noisy, there is a consistent pattern that the level of the outcome variable changes when dental coverage expands.

\section{$5 \quad$ Heterogeneous Effects by Poverty Rate}

Our main results estimate the changes to dental practices that occur within a state when that state adds or drops adult dental benefits from Medicaid. However, much of the concern about access to care following the ACA health insurance expansions focuses on low-income areas, where the gains in coverage will be greatest and the existing capacity may be lowest. Similarly, poor counties may be disproportionately affected when states change Medicaid dental benefits, as counties with high levels of poverty have a larger fraction of the population enrolled in Medicaid and therefore experience larger shocks to the demand for dental care when states add or drop Medicaid adult dental benefits. In this section, we examine whether dentists practicing in high poverty areas exhibit a differential response to changes in Medicaid dental coverage than dentists practicing in low poverty areas. ${ }^{12}$

To conduct this analysis, we assign dentists to the high poverty or low poverty category

\footnotetext{
${ }^{12}$ It would also be informative to examine the effects of these reforms on dentists who did not accept Medicaid patients either before or after the dental coverage expansions. However, because we do not have panel information on the surveyed dentists, we are not able to stratify the data in this way. Furthermore, the Medicaid policy itself affects the participation choice of dentists, making it difficult to interpret heterogeneous effects across dentists who choose and do not choose to participate in Medicaid. Nevertheless, a naive estimate of the effects of the Medicaid policy reveals much larger effects among dentists who report seeing some publicly insured patients, and no significant effects among dentists who report seeing no publicly insured patients.
} 
based on the poverty rate in the county in which they practice. Dentists that practice in counties where the poverty rate is above the median - that is, more than 11.9 percent of the population are impoverished - are classified as practicing in "high poverty" counties. Other dentists are classified as practicing in "low poverty" counties. We then estimate model (1) separately for these two groups of dentists. Because we are stratifying on area-level characteristics, we include only practice-level characteristics as controls in these models.

The results are presented in Table 8 . Here, the asterisks indicate that the coefficient differs significantly from zero, while the hashtags indicate that the estimates for high poverty and low poverty practices differ significantly from each other. As might be expected, we find that the supply of dental services is more sensitive to Medicaid policy in high poverty areas than in low poverty areas. When Medicaid provides dental coverage to adults, the percent of patients covered by public insurance increases more for dentists practicing in high poverty areas than for dentists practicing in low poverty areas. There is a similar difference in the percent of gross receipts collected from the government, although it is not statistically significant. We do not find that the increase in the fraction of dentists accepting any publicly insured patients is greater in high poverty counties. However, dentists practicing in high poverty counties are more likely to accept Medicaid than their low poverty counterparts even when adults do not have dental coverage through Medicaid: forty-four percent of dentists practicing in high poverty counties have some publicly insured patients, relative to 37 percent of dentists in low poverty counties.

The expansion of Medicaid coverage leads dentists in high poverty counties to increase the number of visits they supply by substantially more than dentists in low poverty counties. Emergency or walk-in visits increase by roughly 5 times as much among dentists in the high poverty counties relative to dentists in the low poverty counties. Hygienist visits increase by approximately 3 times as much and visits to publicly insured patients increase by twice as much. The total number of visits supplied increases by 2.5 times more among dentists practicing in high poverty counties, although the difference between the two categories of dentists is not statistically significant for this variable. Both dentists who practice in the high and low poverty counties significantly increase the number of walk-in and hygienists 
visits they provide following the expansion of Medicaid dental coverage, but the increase in total visits and visits to publicly insured patients is only significantly different from zero among the dentists practicing in high poverty counties.

We also find significant differences across high and low poverty counties in the effect of Medicaid coverage on labor supply and employment practices. For dentists' weekly hours, the coefficient on Full is 0.94 for high poverty counties and 0.07 for low poverty counties. Dentists in high poverty counties also experience a larger increase in income and a larger increase in the probability that they employ a hygienist when Medicaid provides dental coverage to adults. Both dentists in high and low poverty counties experience similar increases in wait times when Medicaid begins covering dental care. The increase in the amount of time spent in the waiting room is higher for dentists in high poverty counties, although the difference is not statistically significant.

Overall, we find significantly stronger effects of the Medicaid coverage policy changes among dentists who are likely to have been more affected. Interestingly, the supply response that occurs in the high poverty counties appears to be large enough to address the new demand for dental care, as evidence by the substantially larger increase in the provision of visits and the lack of significantly different changes in wait times for appointments.

\section{Heterogeneous Results by Scope of Practice Laws}

The results presented in Tables 4 and 5 indicate that much of the increase in visits involves care provided by hygienists, and that dentists are more likely to employ hygienists when public insurance coverage expands. This suggests that one way to meet the demand caused by a coverage expansion is via delivery models that make more effective use of hygienists. In the case of dental care, this generally would entail expanding the scope of practice for hygienists. In the case of medical care, this means expanding the scope of practice of nurse practitioner and physicians assistants.

The degree to which a dental hygienist can practice without direct supervision of a dentist 
varies across states. For example, in Colorado, dental hygienists can provide dental hygiene services independently without the oversight of a dentist. In this state, dentists and dental hygienists are "perfect substitutes" for the production of dental hygiene services. In contrast, Georgia requires that dental hygienists perform their duties under the direct supervision of a dentist. In this state, dentists and dental hygienists are closer to "perfect complements." During the period of our analysis, several states changed their scope of practice laws to allow dental hygienists greater autonomy. These reform efforts vary by state, though several reform components are highly correlated. One policy that is particularly relevant to analysis is legal permission for hygienists to bill Medicaid directly. Table 9 summarizes the state variation in this policy. ${ }^{13}$ Fifteen states allow dental hygienists to directly bill Medicaid and 35 states do not. We use this measure, provided by American Dental Hygienist Association (2010), to see if the effects of the public dental insurance expansions differ across states with more or less liberal scope of practice environments.

To conduct this analysis, we interact our measure of whether the state provides full dental coverage with a binary variable indicating that dental hygienists are able to directly bill Medicaid in the state. The interaction model is

$$
\begin{aligned}
Y_{i s t}= & \beta_{s}+\beta_{t}+\beta_{1} \text { Full }_{s t}+\beta_{2} \text { BillMedicaid }_{s t}+\beta_{3} \text { Full }_{s t} \times \text { BillMedicaid }_{s t} \\
& +\beta_{4} X_{i}+\beta_{5} Z_{i}+\epsilon_{i s t} .
\end{aligned}
$$

In this interaction model, the coefficient $\beta_{1}$ measures the effect of expanding dental coverage in states that do not allow hygienists to bill Medicaid directly. Because several states changed their scope of practice laws during the period of our analysis, we can also identify the main effect of this policy, which is represented by $\beta_{2}$, though our primary interest is the coefficient on the interaction term, $\beta_{3}$. This parameter measures the difference between the effect of Medicaid dental coverage in states that do and do not allow dental hygienists to directly bill Medicaid. We present results from this model in Table 10.

\footnotetext{
${ }^{13}$ Other measures of the autonomy of dental autonomy, e.g. the presence of a law that allows hygienists to practice independently in certain settings, generate similar estimates. In general, measures of dental hygienist autonomy are highly correlated. For example, most states that allow dental hygienists to practice independently in some contexts also allow them to bill Medicaid directly.
} 
Although more liberal scope of practice laws are commonly viewed as inducing greater competition between different classes of providers, our results suggests that they may also changes the production function of a dental practice in such a way that makes dentists better able to meet increases in demand. We find that Medicaid dental coverage expansions increase visits with dental hygienists about twice as much in states where hygienists have greater autonomy, although the difference in the effect is not statistically significant. We also find that in states where dental hygienists can bill Medicaid directly, expanding dental coverage causes dentists to hire significantly more dental hygienists.

Additional results suggest that by increasing the ability of providers to to meet increased demand, more liberal scope of practice laws mitigate the negative spillover effects associated with large public coverage expansions. We see that the positive effect of coverage expansions on wait times observed in the full sample is driven by dental practices in states where dental hygienists cannot directly bill Medicaid. In those states, providing dental coverage to adult Medicaid beneficiaries results in an increase in wait time of over 1.19 days for established patients and 0.87 days for new patients, increases of 16 and 10 percent respectively. In contrast, states where dental hygienists can bill Medicaid directly experience no significant increase in wait time for an appointment. The point estimate for the effect of public coverage expansion on wait time for an appointment for these states is remarkably close to zero. We find similar results for the amount of time an established patient spends in the waiting room; states that allow dental hygienists to bill Medicaid directly experience lower increases in waiting room time, although the difference is not statistically significant.

We estimate similar regressions using practice income as the dependent variable. Consistent with prior studies (Kleiner and Park (2010), Marier and Wing (2014)), our results imply that the direct effect of liberal scope of practice laws on dentists income is negative. However, the interaction between the two state policy variables is positive.

Taking the results on visits, employment practices, wait times and practice income together, it appears that in states with more liberal scope of practice laws dental practices are better able to expand supply in response to a coverage expansion. An additional explanation for the wait time results (though not for the results on visits, employment of hygienists and 
practice income) is that in those states patients have a greater range of options, which means less crowding at any particular practice. Consistent with this explanation, we find comparable effects when we stratify the data by the per capita number of dentists in a county. In counties where there are relatively few dentists, we find that expanding Medicaid coverage leads to larger increases in wait times and smaller increases in participation. ${ }^{14}$

\section{Conclusion}

A large and growing number of non-elderly adults are covered by public insurance, and the Affordable Care Act is scheduled to dramatically increase public insurance coverage in the next few years. However, providing coverage is not the same thing as providing access to services. If health care providers are already at or near capacity, this expansion of public coverage may simply result in longer wait times without actually increasing the amount of health care services that patients receive. Alternatively, if health care providers are able to increase the amount of care they supply, either by increasing their labor supply or changing the way they practice, these negative spillover effects may be at least partially mitigated. Understanding how providers respond to public health insurance expansions is therefore crucial in evaluating the costs, benefits, and incidence of coverage expansions. However, despite its importance, very little evidence exists on this topic.

In our analysis, we provided such evidence by analyzing several large increases and decreases in public insurance coverage for a common and important type of primary care: dental services. The market for dental care resembles the market for other types of primary medical care in several important ways, including its focus on prevention and use of midlevel health professionals (hygienists) to deliver care. In particular, both types of care are experiencing similar health professional shortages across the country, raising concerns about access to care as public coverage expands (U.S. Department of Health and Human Services $(2013))$.

Over the last ten years, many states have added or dropped dental benefits from their

\footnotetext{
${ }^{14}$ These additional results are available upon request.
} 
adult Medicaid program, resulting in large and sudden changes in the fraction of state residents with dental insurance. We find that when states expand dental coverage to adult Medicaid recipients, dentists respond by increasing their participation in the Medicaid program and seeing more publicly insured patients without decreasing the amount of care they provide to privately insured patients. They accomplish this by modestly increasing the number of hours they spend treating patients per week and by making greater use of dental hygienists. As a result, dentists' income increases. Our results also indicate that these insurance expansions created negative spillovers: both wait times for appointments and the amount of time a typical patient spends in the waiting room increase, although modestly. These effects are largest for dentists practicing in poor counties, where more residents are covered by the Medicaid program.

We find that the provision of services by dental hygienists is an important channel through which dentists meet the new demand for care when public coverage expands. When states add dental benefits to Medicaid, the increase in the number of visits provided by dental hygienists is approximately one third larger than the increase in visits provided by the dentist. Dentists become more likely to employ hygienists, and employ them in greater numbers. Furthermore, we find significant heterogeneity in the effect of the insurance expansions on wait times across states with different scope of practice laws governing dental hygienists. States that allow hygienists to practice with greater autonomy, as measured by their ability to directly bill Medicaid for services rendered, experience no increase in wait times, while states with more restrictive scope of practice laws experience substantially larger increases in wait time. These results suggest that mid-level health professionals, such as nurse practitioners in the primary medical care context, allow providers the flexibility to adjust capacity when the demand for care increases.

Our results suggest that providers change the way they practice on several margins when faced with a large increase in demand caused by a public health insurance expansion. At least in the market for dental care, we find that enough capacity exists to largely address the increase in demand for dental care that accompanies a large increase in public dental coverage, resulting in only modest increases in wait times. 


\section{References}

Abadie, A., A. Diamond, and J. Hainmueller (2010). Synthetic control methods for comparative case studies: Estimating the effect of california's tobacco control program. Journal of the American Statistical Association 105(490), 493-505.

Academy of General Dentistry (2010). Dental hygienist duties by state. Academy of General Dentistry Report, downloaded from http://www.agd.com/.

Aizer, A. (2007). Public health insurance, program take-up, and child health. The Review of Economics and Statistics 89(3), 400-415.

American Dental Hygienist Association (2010). States which directly reimburse dental hygienists for services under the Medicaid program.

Baker, L. and A. Royalty (2000). Medicaid policy, physician behavior, and health care for the low-income population. Journal of Human Resources, 480-502.

Beck, J., R. Garcia, G. Heiss, P. Vokonas, and S. Offenbacher (1996). Periodontal disease and cardiovascular disease. Journal of Periodontology 67(10), 1123-1137.

Bertrand, M., E. Duflo, and S. Mullainathan (2004). How much should we trust differencesin-differences estimates? The Quarterly Journal of Economics 119(1), 249-275.

Brodsky, S. (2013). Is prevention worth the price? Evidence from Medicaid dental care coverage. Working Paper, University of Michigan.

Buchmueller, T., S. Orzol, and L. D. Shore-Sheppard (2013). The effect of medicaid payment rates on access to dental care among children. NBER Working Paper.

Buchmueller, T. C., K. Grumbach, R. Kronick, and J. G. Kahn (2005). The effect of health insurance on medical care utilization and implications for insurance expansion: A review of the literature. Medical Care Research and Review 62 (1), 3-30.

Card, D., C. Dobkin, and N. Maestas (2007). The impact of nearly universal insurance coverage on health care: Evidence from Medicare. American Economic Review 98(5), 2242-2258. 
Card, D. and L. Shore-Sheppard (2004). Using discontinuous eligibility rules to identify the effects of the Federal Medicaid expansions on low-income children. The Review of Economics and Statistics 83(1), 752766.

Centers for Medicare and Medicaid Services (2013). Medicare and medicaid statistical supplement. Retrieved from http://www.cms.gov on 10/07/2013.

Choi, M. K. (2011). The impact of Medicaid insurance coverage on dental service use. Journal of Health Economics 30(5), 1020-1031.

Cohen, L., R. Manski, L. Magder, and C. Mullins (2002). Dental visits to hospital emergency departments by adults receiving Medicaid: assessing their use. Journal of the American Dental Association 133(6), 715-724.

Congressional Budget Office (2013). February 2013 estimate of the effects of the affordable care act on health insurance coverage. Retrieved from http://www.cbo.gov/ on October 4, 2013.

Currie, J. and J. Gruber (1996). Health insurance eligibility, utilization of medical care, and child health. Quarterly Journal of Economics 11(2).

De Oliveira, C., R. Watt, and M. Hamer (2010). Toothbrushing, inflammation, and risk of cardiovascular disease: results from Scottish health survey. British Medical Journal $340(\mathrm{c} 2451)$.

Decker, S. (2011). Medicaid payment levels to dentists and access to dental care among children and adolescents. Journal of the American Medical Association 306(2), 187-193.

Finkelstein, A., S. Taubman, B. Wright, M. Bernstein, J. Gruber, J. P. Newhouse, H. Allen, K. Baicker, and the Oregon Health Study Group (2012). The Oregon health insurance experiment: Evidence from the first year. Quarterly Journal of Economics 127(3).

Garthwaite, C. (2012). The doctor might see you now: The supply side effects of public health insurance expansions. American Economic Journal: Economic Policy 4(3), 190215. 
Kleiner, M. M. and K. Park (2010). Battle among licensed occupations: Analyzing government regulations on labor market outcomes for dentists and hygienists. NBER Working Paper No. 16560.

Kolstad, J. T. and A. E. Kowalski (2012). The impact of an individual health insurance mandate on hospital and preventive care: Evidence from Massachusetts. Journal of Public Economics 96, 909-929.

Lee, H., C. Lewis, B. Saltzman, and H. Starks (2012). Visiting the emergency department for dental problems: Trends in utilization, 2001 to 2008. American Journal of Public Health 102(11), 77-83.

Marier, A. and C. Wing (2014). Effects of ocupational regulations on the cost of dental services: Evidence from dental insurance claims. Journal of Health Economics 34, 131143.

Miller, S. (2012). The impact of the Massachusetts health care reform on health care use among children. American Economic Review Papers and Proceedings 102(3), 502-507.

Nasseh, K. and M. Vujicic (2013). Health reform in Massachusetts increased adult dental care use, particularly among the poor. Health Affairs 32(9), 1639-45.

Sloan, F., J. Mitchell, and J. Cromwell (1978). Physician participation in state medicaid programs. The Journal of Human Resources 13, 211-245.

Thoden van Velzen, S., L. Abraham-Inpijn, and W. Moorer (1984). Plaque and systemic disease: a reappraisal of the focal infection concept. Journal of Clinical Periodontology 11, 209-220.

U.S. Department of Health and Human Services (2013). Designated health professional shortage areas (hpsa). HSS Report.

U.S. General Accounting Office (2000). Dental disease is a chronic problem among lowincome populations. GAO/HEHS=00-72. 
Wall, T. and K. Nasseh (2013). Dental-related emergency department visits on the increase in the united states. Health Policy Resources Center Research Brief, American Dental Association.

Wallace, N., M. Carlson, D. Mosen, and J. S. B. Wright (2011). The individual and program impacts of eliminating medicaid dental benefits in the oregon health plan. American Journal of Public Health 101(11), 2144-2150.

Yarbrough, C., M. Vujicic, and K. Nasseh (2013). More than 8 million adults could gain dental benefits through Medicaid expansion. American Dental Association Health Policy Resources Center Research Brief. 
Figure 1: Utilization Across Types of Care

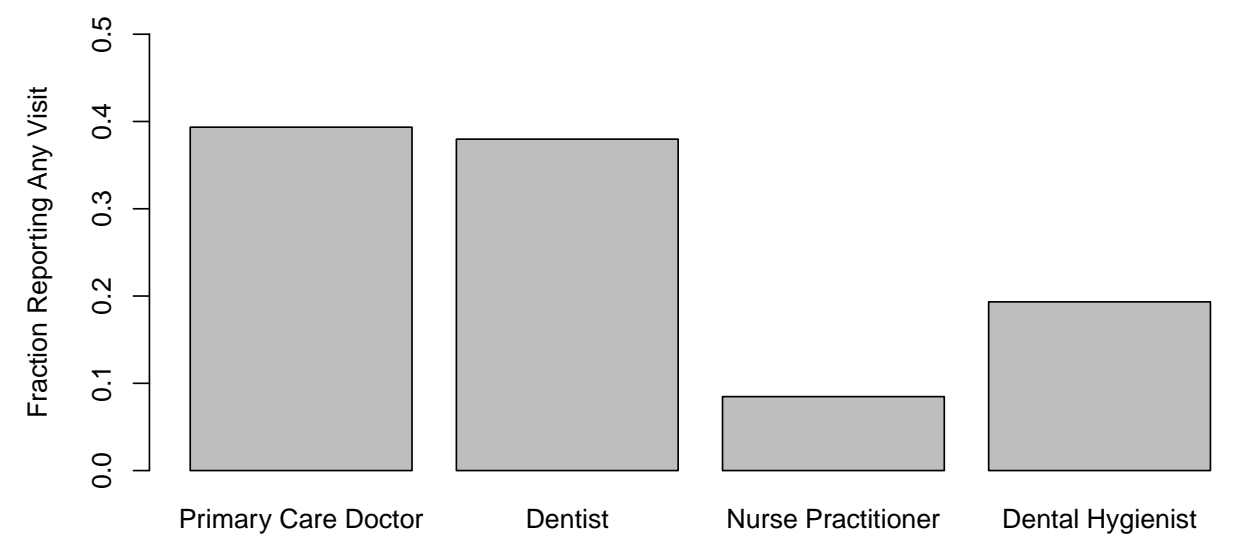

(a) Fraction of non-elderly adults with any visit, by type of visit

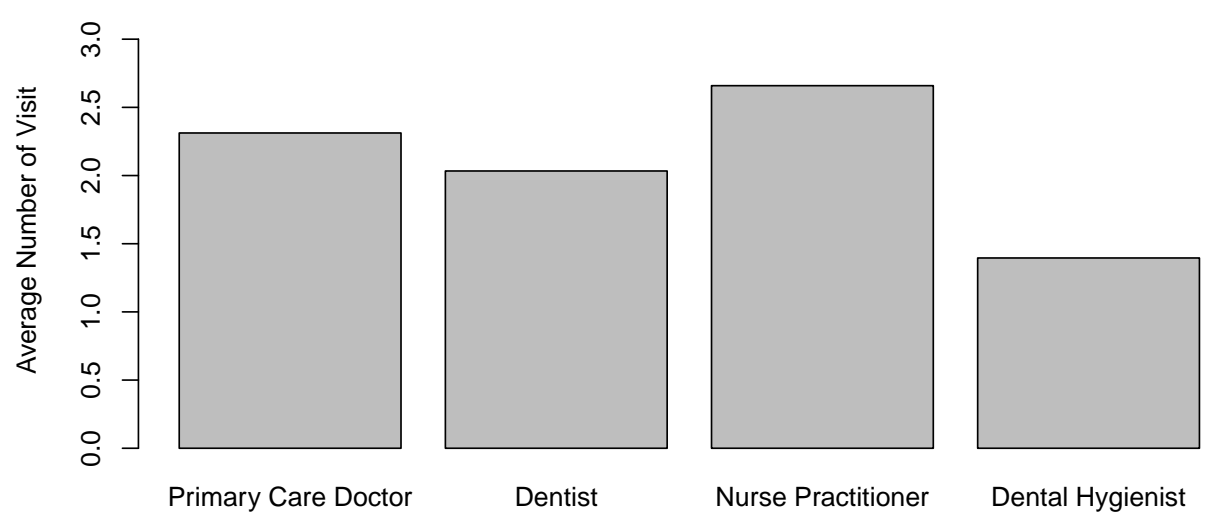

(a) Average \# of visits among non-elderly adults reporting some utilization by category

Note: Authors' calculations from the 2010 Medical Expenditures Survey. Primary care visits are office-based visits with a physician specializing in general practice, family medicine, or pediatrics. Sample includes adults under age 65. 
Figure 2: Full Adult Medicaid Dental Coverage

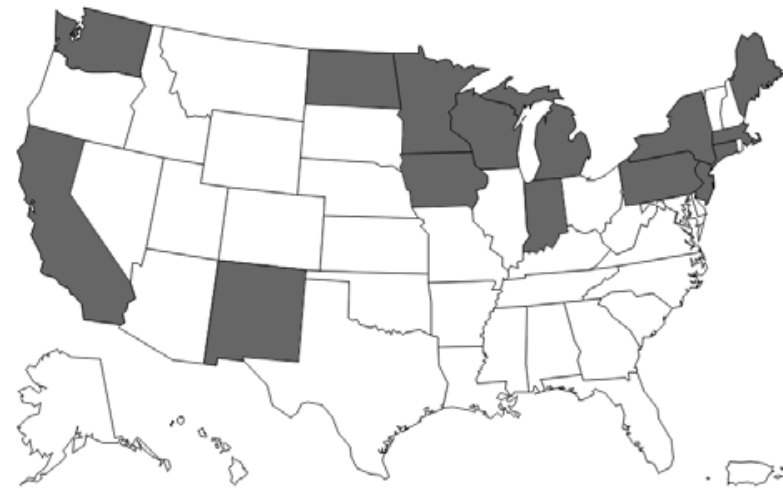

(a) 1999

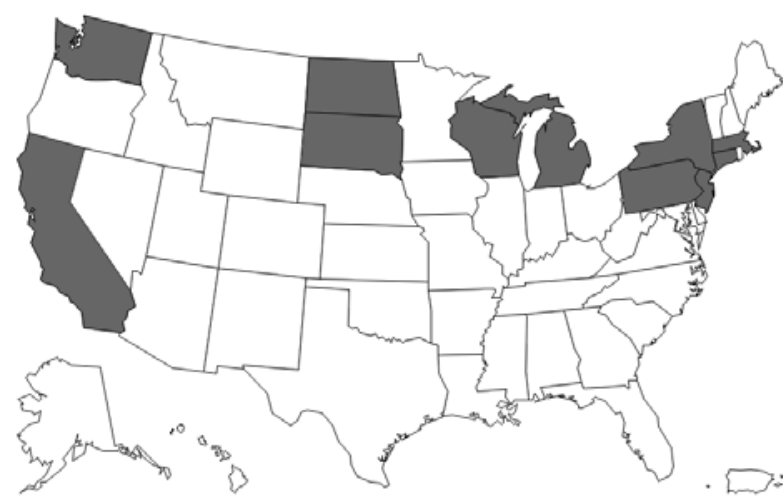

(c) 2008

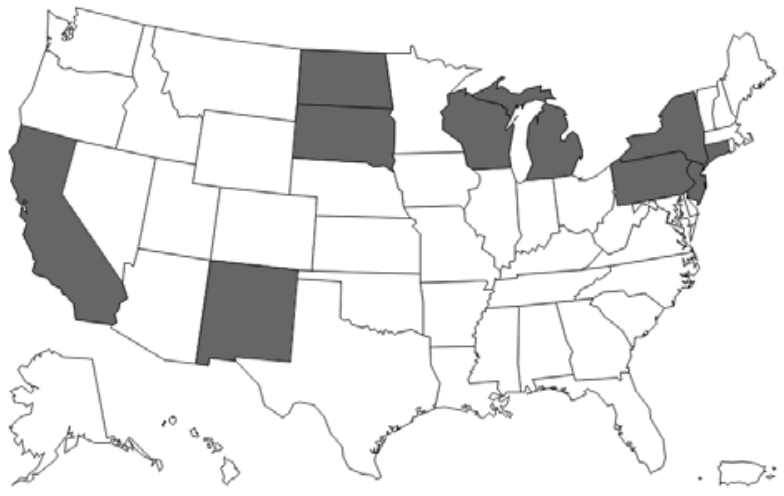

(b) 2003

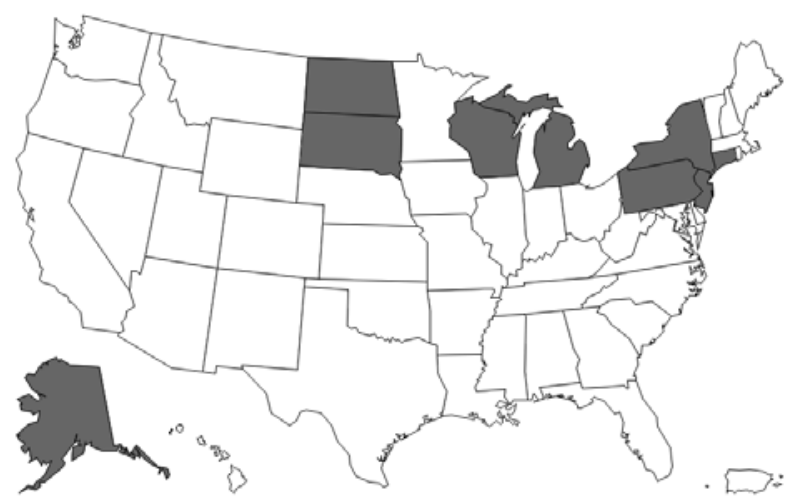

(d) 2011

Note: These maps display the states that provide full dental coverage for adult Medicaid recipients (dark grey) in 1999, 2003, 2008 and 2011. We obtained these classifications from the American Dental Association. 
Figure 3: Provider Response to a Public Health Insurance Coverage Expansion

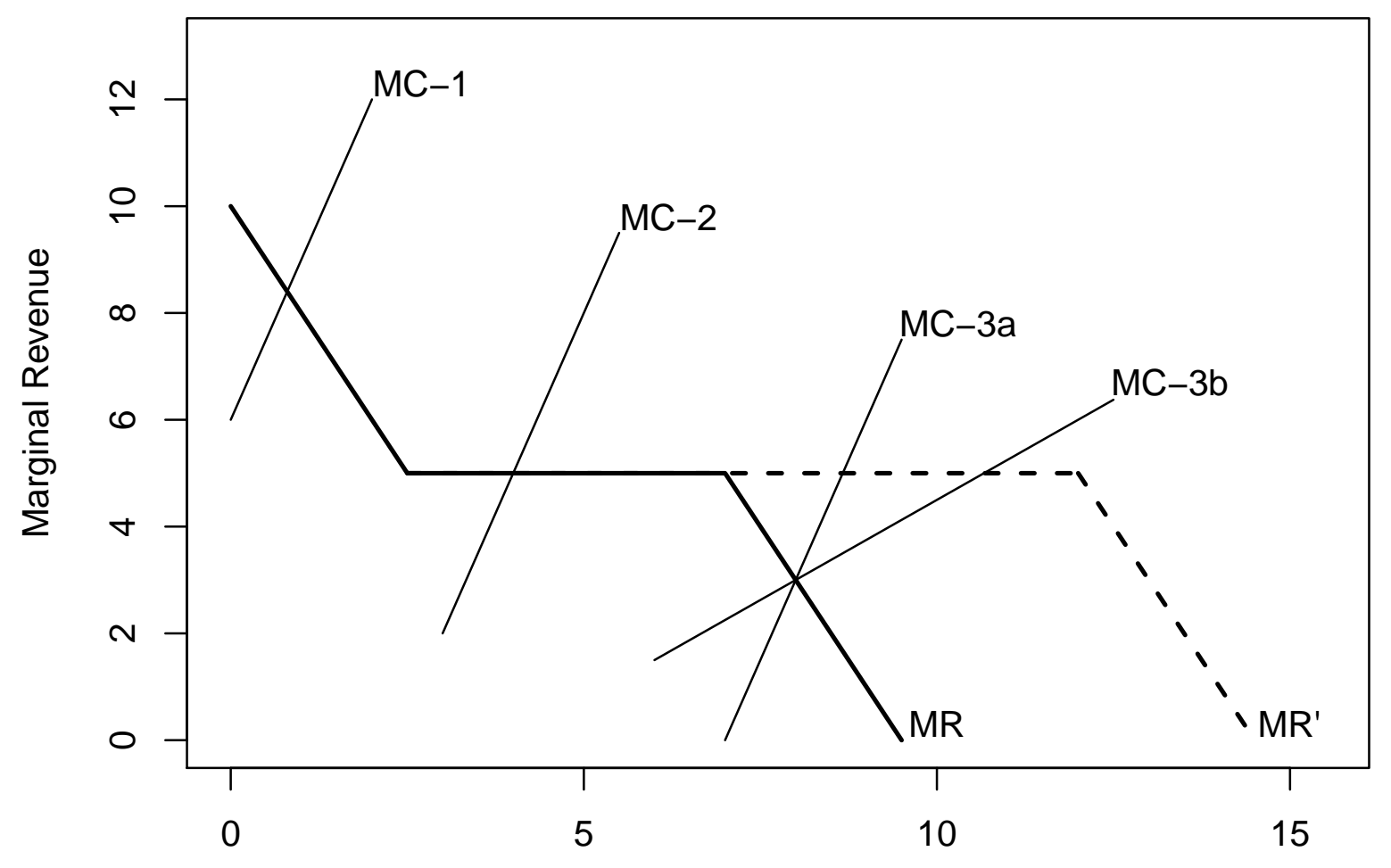

Number of Visits

Note: A simple model of the supply response to a public health insurance expansion, based on Sloan et al. (1978). The effect of an expansion of public health insurance coverage, illustrated by the shift of the marginal revenue curve from MR to MR', will vary across providers with different marginal cost curves. 
Figure 4: Change in Medicaid Adult Dental Coverage: Placebo Effects

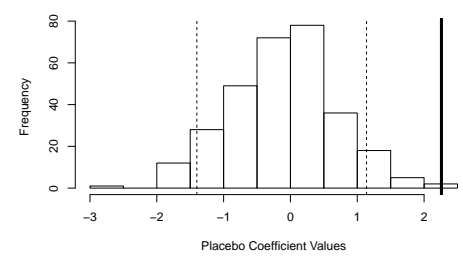

(a) Percent of Patients

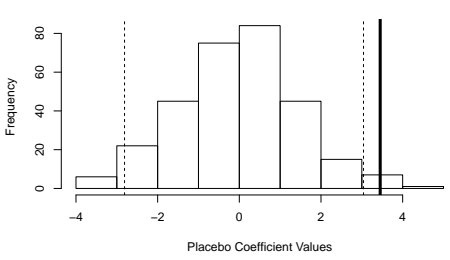

(d) Total Visits per Week

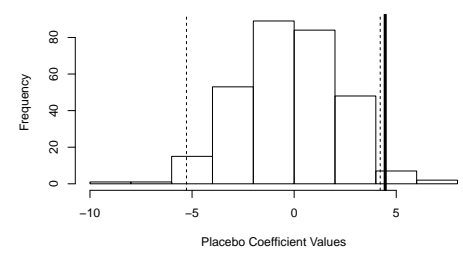

(f) Visits with Hygienist per Week

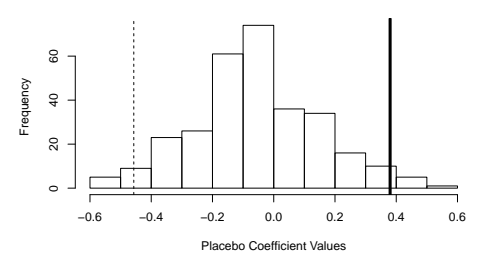

(i) Hours Spent Treating Patients per Week

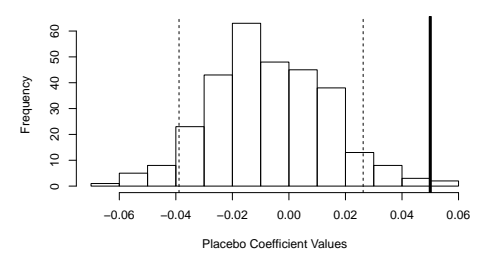

(b) Any Publicly Insured

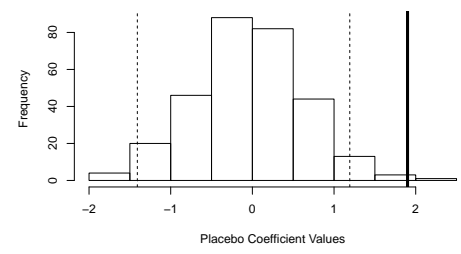

(e) Visits to Publicly Insured Patients per Week

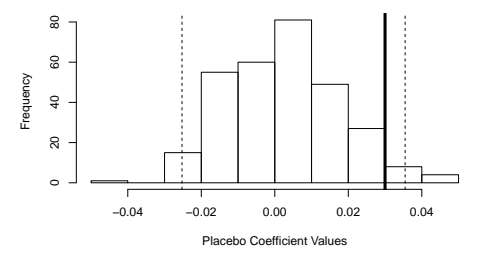

(g) Any Hygienist
Employed

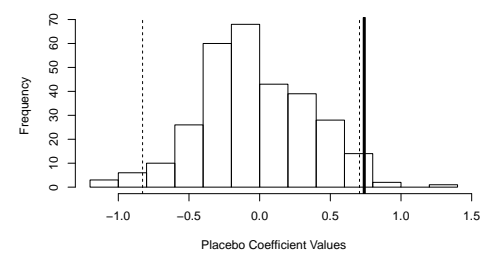

(j) Average \# Days for Appointment

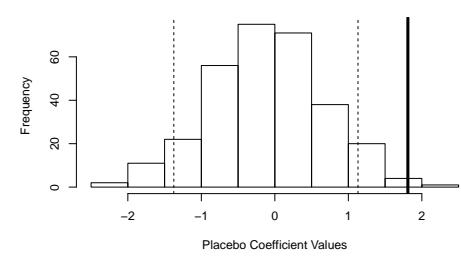
(c) $\%$ Of Gross Receipts
from Govt Payments

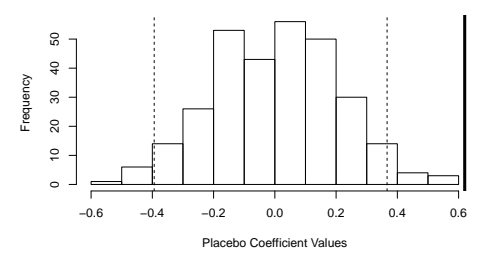
(e) Walk-in or Emergency
Visits per Week

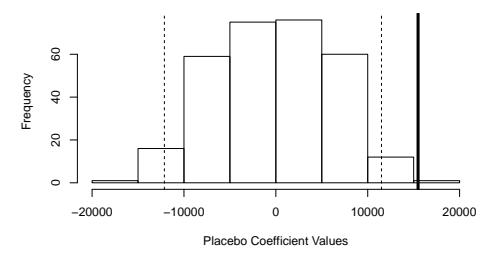

(h) Net Income from
Primary Practice

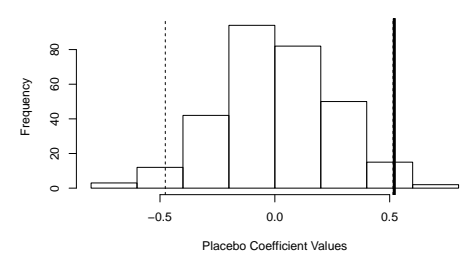

(k) Average \# Minutes in Waiting Room

Note: Histograms plot the frequency of "placebo effects" estimated using states that did not enact a change in Medicaid adult dental benefits. In each of the 300 simulations, an "untreated" state was randomly assigned the treatment pattern of one of the 12 "treated" states and the effects of dental coverage were estimated as if these states had in fact altered their Medicaid dental benefits. The vertical solid line indicates the size of the true effect of adding Medicaid dental coverage, from Column (2) of Tables 3-6. The vertical dashed lines indicate the 97.5th and 2.5th percentiles. The dependent variable is indicated under each histogram. 
Table 1. Changes in Medicaid Adult Dental Coverage by State, 1999 to 2012

\section{Never Covered Adult Dental}

Alabama, Arizona, Arkansas, Colorado, Delaware, Florida, Georgia, Hawaii, Illinois, Kansas, Kentucky, Louisiana, Maryland, Mississippi, Missouri, Montana, Nebraska, Nevada, New Hampshire, North Carolina, Ohio, Oklahoma, Oregon, Rhode Island, South Carolina, Tennessee, Texas, Utah, Vermont, Virginia, West Virginia

\section{Always Covered Adult Dental}

Connecticut, New Jersey, New York, North Dakota, Pennsylvania, Wisconsin, Wyoming

\section{Dropped Adult Dental}

California (2009), Indiana (2003), Iowa (2000), Maine (2000), Minnesota (2003), New Mexico (2004)

\section{Added Adult Dental}

Alaska (2011), District of Columbia (2007), South Dakota (2002)

\section{Dropped and Added Adult Dental}

Massachusetts (dropped 2002, added 2006, dropped 2010),

Michigan (dropped 2004, added 2006, dropped 2009, added 2011),

Washington (dropped 2003, added 2007, dropped 2011) 


\begin{tabular}{|c|c|c|c|}
\hline & Mean & (Std. Dev.) & $\begin{array}{l}\text { Non-missing } \\
\text { observations }\end{array}$ \\
\hline \multicolumn{4}{|l|}{ Participation in Medicaid } \\
\hline Any Publicly Insured Patients $(0,1)$ & 0.39 & $(0.49)$ & 25,423 \\
\hline Percent of Patients Publicly Insured & 6.98 & $(15.58)$ & 25,423 \\
\hline \multicolumn{4}{|l|}{ Percent of Gross Receipts } \\
\hline Government & 5.93 & $(14.28)$ & 20,843 \\
\hline Private insurance company & 51.49 & $(23.83)$ & 20,867 \\
\hline Individual payment & 41.32 & $(24.81)$ & 20,871 \\
\hline \multicolumn{4}{|l|}{ Visits } \\
\hline Average number of visits per week & 61.2 & $(53.6)$ & 26,166 \\
\hline Average number of emergency/walk-in visits per week & 5.42 & $(6.0)$ & 26,289 \\
\hline Average number of visits to hygienist per week & 51.97 & $(65.8)$ & 17,313 \\
\hline Visits to publicly insured patients per week & 5.46 & $(16.23)$ & 23,699 \\
\hline Visits to privately insured patients per week & 37.7 & $(33.4)$ & 23,698 \\
\hline Visits to uninsured patients per week & 18.8 & $(25.4)$ & 23,701 \\
\hline Average visit length (in minutes) & 46.1 & $(39.57)$ & 25,365 \\
\hline \multicolumn{4}{|l|}{ Income, Labor Supply, Employment of Hygienists } \\
\hline Net income from primary and secondary practice & $\$ 223,648$ & $(\$ 169,874)$ & 21,285 \\
\hline Hours worked per week & 35.4 & $(9.0)$ & 32,526 \\
\hline Hours spent treating patients per week & 31.7 & $(7.6)$ & 32,803 \\
\hline Number of hygienists employed & 1.43 & $1.95)$ & 26,291 \\
\hline \multicolumn{4}{|l|}{ Wait Time } \\
\hline Average \# days to wait for appt (established patient) & 7.3 & $(9.2)$ & 26,441 \\
\hline Average \# days to wait for appt (new patient) & 8.6 & $(11.4)$ & 26,174 \\
\hline Average time in waiting room, in min. (estab. patient) & 7.9 & $(7.0)$ & 26,929 \\
\hline Average time in waiting room, in min. (new patient) & 8.5 & $(7.8)$ & 26,053 \\
\hline \multicolumn{4}{|l|}{ Dentist Characteristics } \\
\hline Owner or partner in practice $(0,1)$ & 0.90 & $(0.3)$ & 33,761 \\
\hline Number of dentists in practice & 1.9 & $(2.8)$ & 33,811 \\
\hline Years practicing & 18.6 & $(12.0)$ & 32,636 \\
\hline General practitioner $(0,1)$ & 0.55 & $(0.50)$ & 33,811 \\
\hline
\end{tabular}


Table 3. The Effect of Medicaid Dental Coverage on Program Participation and Practice Revenue

(1)

(2)

\section{Program Participation}

1. Any Publicly Insured Patients $(0,1)$

$0.06^{* * *} \quad 0.05^{* * *}$

$(0.02) \quad(0.02)$

2. Percent Publicly Insured

$2.48 * * * \quad 2.27 * * *$

$(0.82)$

\section{Percent of Gross Practice Receipts by Source}

\begin{tabular}{rll} 
3. Government & $1.86^{* *}$ & $1.82^{* * *}$ \\
& $(0.73)$ & $(0.40)$ \\
4. Direct Payment from Individuals & $-1.52^{* * *}$ & $-2.04^{* * *}$ \\
& $(0.46)$ & $(0.52)$ \\
5. Payment from Private Insurance & -0.16 & 0.40 \\
& $(0.93)$ & $(0.61)$ \\
\hline \multirow{2}{*}{ Practice and Area-Level Controls? } & No & Yes \\
\hline \hline
\end{tabular}

Notes: Each row presents results from a different regression model and reports the estimated coefficient on an indicator variable that equals one if the state provides full dental coverage to adult Medicaid enrollees, and zero otherwise. All models include state and year fixed effects. The models in column (2) also include practice characteristics (dentist is a general practitioner $(0,1)$, dentist owns the practice $(0,1)$, number of dentists in the practice, number of years practicing), county level covariates (unemployment rate, percent of the population that is black, percent of the population under the age of 18, and percent in poverty), and state level covariates (gross state product, percent uninsured). Robust standard errors are clustered by state.

$* * *$ p-value $<.01$ level; $* * .01<$ p-value $<.05 ; .05<$ p-value $<.10$ 
Table 4. The Effect of Medicaid Dental Coverage on Dental Visits

(1)

(2)

1. Total visits

$2.75^{*}$

$3.45^{* *}$

By Patient Insurance Status

2. Number of visits, uninsured

$-0.12$

0.18

3. Number of visits, privately insured

$(0.53)$

$(0.50)$

1.12

1.28

$(0.97)$

$(0.91)$

4. Number of visits, publicly insured

$2.22 * * *$

$2.09 * * *$

$(0.58)$

$(0.41)$

\section{By Type of Visit}
5. Emergency/walk-in visits
$0.47 * *$
$0.62 * * *$
$(0.19)$
$(0.22)$
6. Visits with hygienists
$6.13 * * *$
$4.46^{* * *}$
(1.28)
(1.20)
7. Average \# hygienist visits per dentist
$4.24 * * *$
$3.78 * * *$
$(0.96)$

\section{Visit Characteristics}
8. Average length of visit with dentist
$-0.09$
$-0.99$ (in minutes)
(0.74)
(0.76)

Practice and Area-Level Controls?

No

Yes

Notes: Each row presents results from a different regression model and reports the estimated coefficient on an indicator variable that equals one if the state provides full dental coverage to adult Medicaid enrollees, and zero otherwise. All models include state and year fixed effects. The models in column (2) also include practice characteristics (dentist is a general practitioner $(0,1)$, dentist owns the practice $(0,1)$, number of dentists in the practice, number of years practicing), county level covariates (unemployment rate, percent of the population that is black, percent of the population under the age of 18 , and percent in poverty) and state level covariates (gross state product, percent uninsured). Robust standard errors are clustered by state.

$* * *$ p-value $<.01$ level; $* * .01<$ p-value $<.05 ; * .05<$ p-value $<.10$ 
Table 5. The Effect of Medicaid Dental Coverage on Dentists' Labor Supply, Income, and Employment Practices

(1)

\section{Labor Supply}

1. Hours spent treating patients per week

2. Hours worked per week

Employment of Hygienists

3. Number of hygienists (\#)

4. Hourly earnings of hygienists

5. Any hygienist employed $(0,1)$
$0.55 * * *$

$(0.14)$

$0.43^{* *}$

(0.16)

$\begin{array}{cc}0.15^{*} & 0.09^{* *} \\ (0.07) & (0.04)\end{array}$

$0.38^{* * *}$

0.24

(0.23)

$0.52 \quad 0.13$

(0.41) (0.36)

$0.03 * * \quad 0.03 * *$

$(0.01) \quad(0.01)$

\section{Income Source}

6. Primary and secondary practice

$20480.83 * * *$

(3750.42)

$15477.01 * * *$

(3938.61)

7. Other income from dentistry (e.g.,

609.35

957.54 teaching, research, tertiary practice)

(766.83)

(979.99)

Practice and County-Level Controls?

No

Yes

Notes: Each row presents results from a different regression model and reports the estimated coefficient on an indicator variable that equals one if the state provides full dental coverage to adult Medicaid enrollees, and zero otherwise. All models include state and year fixed effects. The models in column (2) also include practice characteristics (dentist is a general practitioner $(0,1)$, dentist owns the practice $(0,1)$, number of dentists in the practice, number of years practicing), county level covariates (unemployment rate, percent of the population that is black, percent of the population under the age of 18, and percent in poverty) and state level covariates (gross state product, percent uninsured). Robust standard errors are clustered by state.

$* * *$ p-value $<.01$ level; $* * .01<$ p-value $<.05 ; * .05<$ p-value $<.10$ 
Table 6. The Effect of Medicaid Dental Coverage on Wait Times

(1)

(2)

Wait Time for Appointment (in Days)

1. New patients

$0.40 \quad 0.56$

2. Established patients

$(0.40) \quad(0.39)$

$0.61 * * \quad 0.74 * *$

$(0.30)$

$(0.29)$

Wait Time in Waiting Room (in Minutes)

\begin{tabular}{lcc} 
3. New patients & $0.36^{* * *}$ & $0.54^{* * *}$ \\
& $(0.13)$ & $(0.16)$ \\
4. Established patients & $0.40^{* * *}$ & $0.51^{* * *}$ \\
& $(0.11)$ & $(0.13)$ \\
\hline
\end{tabular}

Practice and County-Level Controls? No Nes

Notes: Each row presents results from a different regression model and reports the estimated coefficient on an indicator variable that equals one if the state provides full dental coverage to adult Medicaid enrollees, and zero otherwise. All models include state and year fixed effects. The models in column (2) also include practice characteristics (dentist is a general practitioner $(0,1)$, dentist owns the practice $(0,1)$, number of dentists in the practice, number of years practicing), county level covariates (unemployment rate, percent of the population that is black, percent of the population under the age of 18 , and percent in poverty), and state level covariates (gross state product, percent uninsured). Robust standard errors are clustered by state.

$* * *$ p-value $<.01$ level; $* * .01<$ p-value $<.05 ; .05<$ p-value $<.10$ 


\section{Table 7. Placebo Tests}

\section{Geographic Neighbors Statistical Neighbors}

\section{Participation}

1. Any Publicly Insured Patients

(1)

(2)

2. Percent of Patients Publicly Insured

3. Percent of Gross Receipts from Government

\section{Visits}

4. Total Visits

5. Emergency/Walk-In Visits
$0.03(0.02)^{*}$
$0.79(0.52)$

$-0.03(0.02)$

$-1.08(0.74)$

$-1.08(0.80)$

$0.53(0.50)$

$2.11(1.27)$

$0.85(2.36)$

$0.02(0.16)$

$0.33(0.20)$

6. Hygienist Visits

$-1.64(2.56)$

$-3.10(1.78)^{*}$

7. Visits to Publicly Insured

$0.21(0.44)$

$-0.49(0.72)$ Patients

\section{Labor Supply, Income and Hygienist}

\section{Employment}

8. Hours Spent Treating Patients per Week

9. Income from Primary and Secondary Practice

10. Any Hygienist $(0,1)$

\section{Wait Time}

11. Days until Appt (Established Patient)

12. Minutes in Waiting Room (Established Patient)

Practice and County-Level Controls?

$0.07(0.24)$

$8724.36(4494.81)^{*}$

$0.0001(0.01)$

$0.57(0.35)$

$0.31(0.16)^{*}$
$0.12(0.20)$

$-14903.89(4923.8) * * *$

$0.002(0.01)$

$-0.05(0.35)$

$-0.06(0.21)$

Notes: Each row presents results from a different "placebo" regression model (see text for details). All models include state and year fixed effects. The models in columns (1) and (2) use placebo states based on geographic location. The models in columns (3) and (4) use placebo states based on state characteristics. The models reported in columns (2) and (4) also include practice characteristics (dentist is a general practitioner $(0,1)$, dentist owns the practice $(0,1)$, number of dentists in the practice, number of years practicing), county level covariates (unemployment rate, percent of the population that is black, percent of the population under the age of 18, and percent in poverty), and state level covariates (gross state product, percent uninsured). Robust standard errors are clustered by state.

$* * *$ p-value $<.01$ level; **.01< p-value $<.05 ; * .05<$ p-value $<.10$ 
Table 8. Heterogeneous Effects of Medicaid Dental by Poverty Rate in County of Practice

\begin{tabular}{|c|c|c|}
\hline & $\begin{array}{l}\text { High Poverty } \\
\text { County }\end{array}$ & $\begin{array}{l}\text { Low Poverty } \\
\text { County }\end{array}$ \\
\hline \multicolumn{3}{|l|}{ Participation } \\
\hline 1. Any Publicly Insured Patients & $\begin{array}{c}0.04 \\
(0.03)\end{array}$ & $\begin{array}{l}0.06 * * * \\
(0.02)\end{array}$ \\
\hline 2. Percent of Patients Publicly Insured & $\begin{array}{l}3.70 * * * \neq \neq \\
(1.01)\end{array}$ & $\begin{array}{l}1.99 * * * \neq \neq \\
(0.51)\end{array}$ \\
\hline $\begin{array}{l}\text { 3. Percent of Gross Receipts from } \\
\text { Government }\end{array}$ & $\begin{array}{l}2.41^{* *} \\
(0.89)\end{array}$ & $\begin{array}{l}1.94 * * * \\
(0.60)\end{array}$ \\
\hline
\end{tabular}

Visits

4. Total Visits

$\begin{array}{lc}4.69 * * * & 1.74 \\ (1.72) & (1.54) \\ 1.00 * * * \neq \neq \neq & 0.19 \neq \neq \neq \\ (0.24) & (0.22)\end{array}$

6. Hygienist Visits

$9.74 * * * \neq \neq \neq$

(1.56)

$3.31 * * * \neq \neq \neq$

7. Visits to Publicly Insured Patients

$3.00 * * * \neq \neq$

$(0.81)$

$1.54 * * * \neq \neq$

$(0.35)$

\section{Labor Supply, Income and Hygienist Employment}

8. Hours Treating Patients per Week

$0.94 * * * \neq \neq \neq \quad 0.07 \neq \neq \neq$

$(0.15)$

$(0.25)$

9. Income from Primary and Secondary

$25,593.92 * * *$

$12,895.03 * *$

Practice

(4719.99)

(5356.52)

10. Any Hygienist $(0,1)$

$0.06 * * * \neq \neq \quad 0.02 \neq \neq$

$(0.02)$

$(0.01)$

\section{Wait Time}
11. Days until Appt (Established Patient)
0.34
0.65
$(0.30)$
$(0.41)$
12. Minutes in Waiting Room (Established Patient)
$0.64 * *$
0.24
$(0.25)$
$(0.20)$

Notes: Each row presents results from a different regression model. Column (1) reports the estimated coefficient of a variable that equals to 1 if the state offers full dental coverage for adult Medicaid beneficiaries for dentists who practice in a county with a poverty rate above the median poverty rate of 11.9 percent. Column (2) reports the coefficient a variable equals to 1 if the state offers full dental coverage for adult Medicaid beneficiaries for dentists who practice in a county with a poverty rate below the median poverty rate of 11.9 percent. All models include state and year fixed effects and practice characteristics (dentist is a general practitioner $(0,1)$, dentist owns the practice $(0,1)$, number of dentists in the practice, number of years practicing). Robust standard errors are clustered by state. * indicates significance levels for tests that the coefficients are different from zero. $¥$ indicates significance levels for tests of coefficient equality across the high and low poverty models.

$* * *$ p-value $<.01$ level; **.01< p-value $<.05 ; * .05<$ p-value $<.10$ 
Table 9. Dental Hygienist Scope of Practice Laws by State.

Dental hygienists cannot bill Medicaid directly for services rendered Alabama, Alaska, Arkansas, Delaware, District of Columbia, Florida, Georgia, Hawaii, Idaho, Illinois, Indiana, Iowa, Kansas, Kentucky, Louisiana, Maryland, Michigan, Mississippi, New Hampshire, New Jersey, New York, North Carolina, North Dakota, Ohio, Oklahoma, Pennsylvania, Rhode Island, South Carolina, South Dakota, Tennessee, Texas, Utah, Vermont, Virginia, Washington, West Virginia, Wyoming

Dental hygienists can bill Medicaid directly for services rendered

Arizona (2007), California (1998), Colorado (2001), Connecticut (2001), Maine (2002), Massachusetts (2009), Minnesota (2002), Missouri (2002), Montana (2007), Nebraska (2008), Nevada (2003), New Mexico (2003), Oregon (2000), Washington (2002), Wisconsin (2006)

Notes: Date that direct billing policy enacted is in parentheses. Source: American Dental Hygienist Association report, States which directly reimburse dental hygienists for services under the Medicaid program 2010. 
Table 10. Heterogeneous Effects of Medicaid Dental Coverage by Scope of Practice Laws

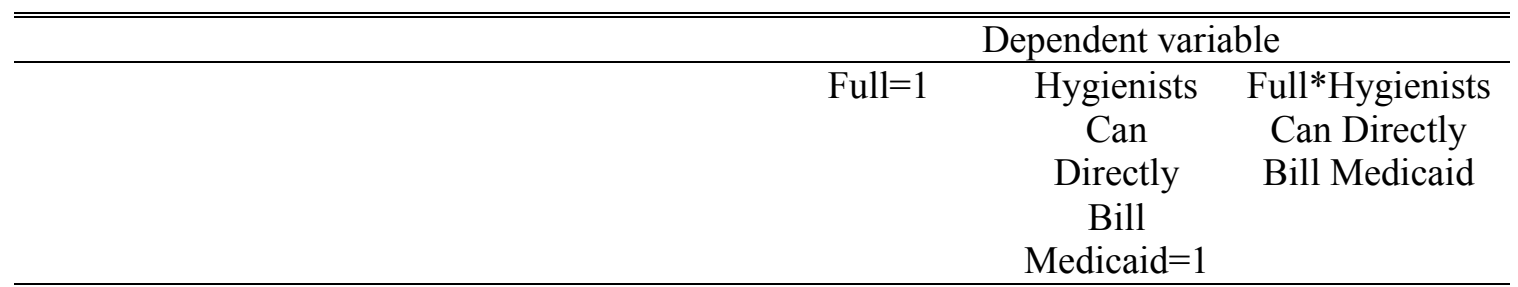

Use of Hygienists

1. Visits with Hygienist

$\begin{array}{llc}3.08 & -0.10 & 3.38 \\ (1.91) & (2.82) & (2.84) \\ -0.04 & -0.08 & 0.24 * * \\ (0.08) & (0.09) & (0.10)\end{array}$

Dentist Labor Supply and Income

2. Number of Hygienists Employed

3. Dentist Hours

4. Dentist Income

Wait Time for Appointment (In Days)

5. Established Patient

6. New Patient

\section{Wait Time in Waiting Room (In Minutes)}

7. Established Patient

8. New Patient

\begin{tabular}{ccc}
0.14 & -0.38 & 0.12 \\
$(0.34)$ & $(0.36)$ & \multicolumn{1}{c}{$(0.36)$} \\
$11740.60^{* * *}$ & $-12976.03 *$ & 5087.55 \\
$4087.52)$ & $(7217.91)$ & $(6375.02)$
\end{tabular}

$\begin{array}{lll}1.19 * * * & -0.20 & -0.92 * * \\ (0.39) & (0.57) & (0.48) \\ 0.87 * * & -1.19 * & -0.84 \\ (0.39) & (0.67) & (0.61)\end{array}$

$\begin{array}{clc}0.58 * * * & -0.15 & -0.16 \\ (0.19) & (0.30) & (0.22) \\ 0.35 * & -0.41 & 0.25 \\ (0.19) & (0.33) & (0.25)\end{array}$

Notes: Each row presents results from a different regression model. Column (1) reports the estimated coefficient of the independent variable that equals to 1 if the state offers full dental coverage for adults on Medicaid. Column (2) reports the coefficient on the independent variable that equals to 1 if hygienists can bill Medicaid directly for services rendered. Column (3) reports the coefficient on the interaction term of these two variables. All models include state and year fixed effects, practice characteristics (dentist is a general practitioner $(0,1)$, dentist owns the practice $(0,1)$, number of dentists in the practice, number of years practicing), county level covariates (unemployment rate, percent of the population that is black, percent of the population under the age of 18 , and percent in poverty) and state level covariates (gross state product, percent uninsured). Robust standard errors are clustered by state.

*** p-value $<.01$ level; ** .01 < p-value $<.05 ; .05<$ p-value $<.10$ 


\section{Not For Publication - For Online Publication Only}

\section{A Alternative Measures of Dental Coverage (Appendix)}

In our main analysis, we evaluate the effect of states adding or dropping "full" dental benefits only. Full dental benefits cover both preventive and emergency dental services and apply to all adult Medicaid beneficiaries. In this section, we explore the extent to which limited and emergency dental coverage policies affect provider behavior. In contrast to full dental benefits, limited dental coverage either a) does not apply to all adult Medicaid beneficiaries (e.g., coverage is only available to pregnant women) or b) does not cover common types of dental care (e.g., restorative services are not covered). Emergency dental coverage covers only emergency tooth extraction. Often, emergency dental care is conducted in the emergency department of hospitals, rather than at dentists' offices (see, e.g., Choi 2012).

To explore the effects of limited and emergency dental coverage, we estimate our main specification (equation (1) in the main text) but also include binary variables Limited and Emergency that equal 1 if the state provides limited or emergency dental benefits, respectively. These classifications are determined by the American Dental Association.

The results are presented in Appendix Table 1. We find that limited and emergency dental services have statistically significant effects on dentist participation in the Medicaid program, although the effects are smaller than those observed when states add full coverage. Limited and emergency dental benefits increase the probability a dentist has any publicly insured patient by 5 percentage points, while full benefits are associated with an increase of 9 percentage points. Full dental benefits increase the percent of a dentists' patients 
who are publicly insured by 3.7 percentage points, limited benefits result in an increase of 2.6 percentage points, and emergency benefits result in an increase of 1.8 percentage points. Similarly, full dental benefits increase the percent of gross receipts received from the government by 2.8 percentage points, limited dental benefits increase this percent by 1.9 percentage points, and emergency dental benefits increase this by a statistically insignificant 0.6 percentage points.

We find no significant effects of limited or emergency dental coverage on the total supply of visits or the number of dental hygienist visits, although the we do find that limited coverage increases the number of visits to publicly insured patients. We do not find that limited or emergency dental benefits significantly increase in the number of hours dentists spend working per week, although we do find a significant increase in dentists' income associated with limited dental benefits. This increase in income associated with limited dental coverage for adult Medicaid recipients is smaller than what we find for full coverage. We also do not find any effect of limited or emergency dental coverage on hygienist employment or wait times. Overall, we conclude that limited and emergency dental benefits have only a small impact on dentists' behavior relatively to full dental benefits.

\section{B Additional Estimates (Appendix)}

In the main text, we only report the coefficient on our outcome of interest. In Appendix Table 2, we report the coefficients on the other independent included in the model with controls for selected outcomes. In Appendix Table 2, the dependent variables are listed in the first row, and the independent variables are listed in the first column. All models include state and year fixed effects (not reported), and the indicator for full dental coverage (reported in the main text). Estimates of the full model for other outcomes are available upon request.

The first four rows present the coefficients on variables describing the dentist and his or her practice. Being a general practitioner is associated with seeing a smaller percentage of public patients, providing fewer visits each week as well as fewer emergency/walk-in visits, 
spending more hours seeing patients, lower income, and a higher likelihood of employing a hygienist. Dentists with an ownership stake in the practice see smaller percentage of public patients than other dentists, provide more visits per week and more emergency/walk-in visits, work longer hours, have higher incomes, and are less likely to employ a hygienist. The number of dentists affiliated with a practice is positively correlated with the percent of patients with public insurance, the number of emergency/walk-in visits per week, the number of hours spent treating patients per week, income, and the probability of employing a hygienist. More experience (years practicing) is associated with a lower percentage of public insured patients, fewer total visits and fewer emergency/walk-in visits, fewer hours worked per week, and lower income.

The next four rows present the coefficients on the control variables describing the characteristics of the county in which the dentist practices. The county poverty rate is positively correlated with the percent of patients with public insurance, total number of visits, and number of emergency/walk-in visits. The fraction of the county who is black is negatively associated with the percent of patients with public insurance, the number of total visits, and the number of emergency/walk-in visits. The unemployment rate of the county is positively correlated with the number of emergency/walk-in visits and negatively correlated with a dentist's income. The fraction of the county population who are under 18 has strong positive correlations with the percent of patients who have public insurance, the number of total visits, the number of emergency or walk-in visits, and the number of hours spent treating patients.

The final two rows present the coefficients on control variables describing the characteristics of the state in which the dentist practices. The percent uninsured in the state is negatively correlated with the percent of patients that a dentist sees who are publicly insured, and the gross state product is positively correlated with hours worked. 


\section{Event Study Figures of the Effect of Dental Cover- age (Appendix)}

Figure 1 provides such descriptive evidence of how changes to state Medicaid policy affect dentists' behavior. This "event study" figure displays the change in our main outcome variables relative to the year when dental services were added or dropped to adult Medicaid benefits. For states that both added or dropped Medicaid dental benefits, we include data from the first change in policy only. The x-axis displays the years from the policy change, with the policy change recorded as year "0." Both states that dropped and added these benefits are displayed on the same graph, but arranged such that the change in policy is always expressed as an adoption (rather than a drop) of benefits. That is, for states that dropped benefits, time is expressed as running from 5 to -5 (from right to left); for states that added benefits, time is expressed as running from -5 to 5 (left to right).

The panel (a) displays the change in the percent of patients who are publicly insured over time. When states cover full dental benefits, this percent is higher, suggesting that expanding coverage increases dentists' participation in the program. Panel (b) displays the total number of visits and panel (c) displays the number of visits to publicly-insured patients hours. Both appear to substantially increase when states add dental benefits to Medicaid coverage. Hours spent treating patients (panel (d)) and the number of full-time hygienists

employed (panel (e)) increase accordingly, suggesting that these are two mechanisms by which providers are able to expand capacity. Income, presented in panel (f), does not noticeably increase following the adoption of Medicaid dental benefits, although the variance of the measure appears to be high. Finally, the number of days it takes to get an appointment (g) and the average amount of time spent in the waiting room (h) both appear to increase significantly when states have provide full dental benefits to Medicaid recipients. 


\section{Construction of county-level adult Medicaid cover- age estimates (Appendix)}

In our discussion of the results, we report estimates that scale the reduced form effects of adding full dental benefits to adult Medicaid coverage by the average fraction of the adult population that has Medicaid coverage. The purpose of this scaling is to provide context for interpreting the reduced form effects, as well as translating these estimates into the effect of an incremental increase in dental insurance coverage (see Section 3.2 in the main text). In this appendix section, we describe how we calculate the fraction of adults in each county who are Medicaid beneficiaries.

For the years 2008 through 2011, we are able to directly calculate the fraction of the adult population that is covered by Medicaid using the American Community Survey (ACS). The ACS provides geographic information by Public Use Microdata Area on Medicaid coverage, and we map these data to counties using a crosswalk provided by the Missouri Census Data Center. ${ }^{1}$

The ACS only included questions related to insurance status beginning in 2008. For years prior to 2008, we construct county level Medicaid coverage figures using state-level Medicaid enrollment information and the 2008 county-level Medicaid beneficiary information from the ACS. To do this, we assume that the county-to-state Medicaid beneficiary ratio remains fixed; that is, we assume that each county maintains the same percent of total state Medicaid beneficiaries, even if the total number of Medicaid beneficiares fluctuates at the state level. We first construct the ratio as

$$
\widehat{\text { Ratio }}=\frac{\# \text { Adult Medicaid Recipients in County in } 2008_{c s}}{\# \text { Adult Medicaid Recipients in State in } 2008_{s}} .
$$

We use data on the annual number of adult Medicaid recipients by state from the Medicaid Statistical Information System (MSIS) State Summary data reports. ${ }^{2}$ These documents report the total number of adult Medicaid enrollees by state for each year. We map this to

\footnotetext{
${ }^{1}$ Downloaded from http://mcdc2.missouri.edu/websas/geocorr2k.html on May 16, 2013.

${ }^{2}$ Downloaded from http://www.cms.gov/Research-Statistics-Data-and-Systems/Computer-Data-andSystems/MedicaidDataSourcesGenInfo/index.html on May 16, 2013.
} 
the county using our constructed ratio as

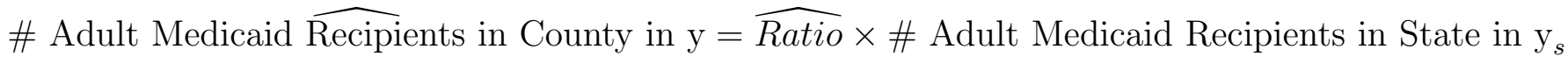

where y ranges from 1999 to 2007. We then divide our estimate of the \# of Adult Medicaid Recipients in County in y by the Census population count of adults to obtain the estimated fraction of the adult population who are Medicaid beneficiaries. In the text, we use this fraction to scale our reduced form estimates. 
Figure 1: Change in Medicaid Adult Dental Coverage: Event Study Figures for Main Outcome Variables

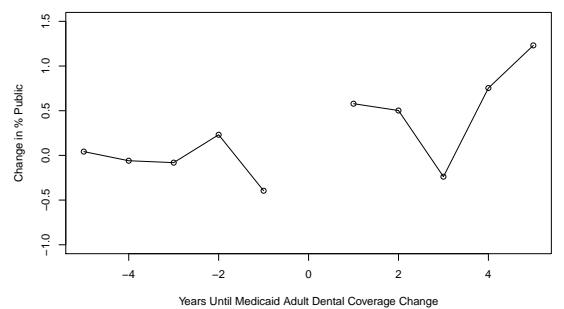

(a) Percent of Patients Publicly Insured

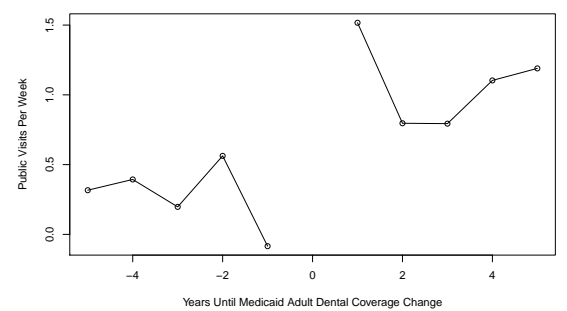

(c) Visits to Publicly-Insured Patients per Week

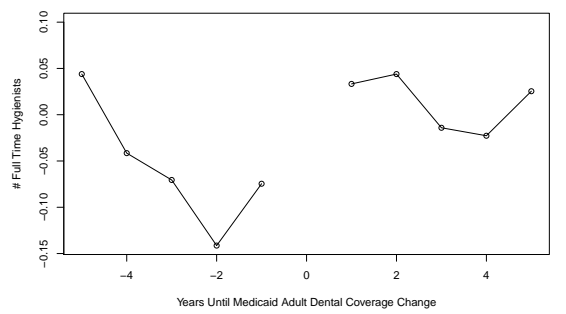

(e) \# Hygienists

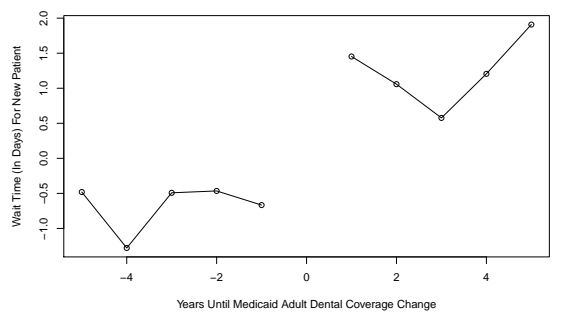

(g) Wait Time for Appt In Days

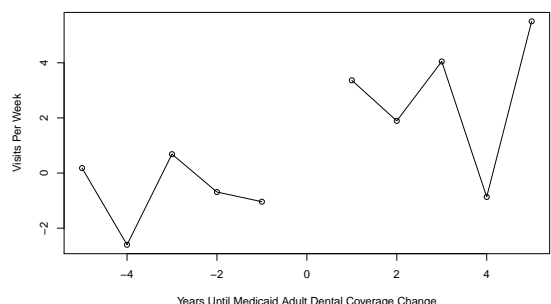

(b) Total Visits

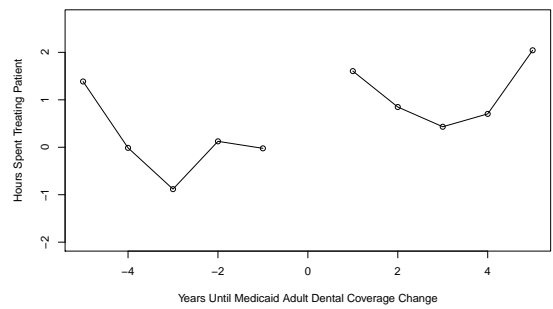

(d) Hours Spent Treating Patients

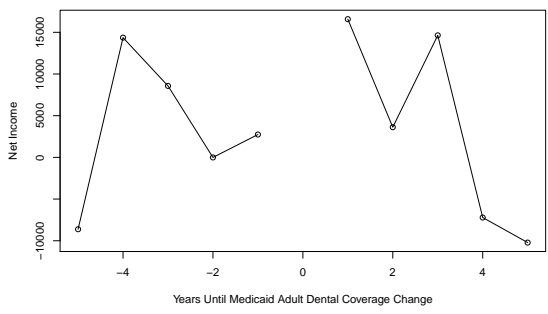

(f) Income from Primary Practice

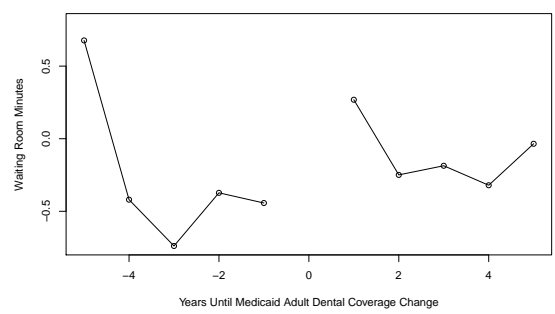

(h) Average \# Minutes in Waiting Room

Note: Graph plots estimates of the change in selected outcomes $t$ years until adult Medicaid dental coverage policy changes (i.e., until full dental coverage for adults is dropped or added). Both states that add (AK, DC, SD) and states that dropped (CA, IN, IA, ME, MN, NM) are included in this figure. Time is ordered such that crossing the 0 position on the $\mathrm{x}$ axis is associated with the indicator for Medicaid full adult dental coverage going from 0 to 1 . We only use the first change for states that both added and dropped Medicaid coverage over the sample period (MA, MI, WA). States that added coverage in 2011, the last year of the sample, are excluded from the figure. 
Appendix Table 1. Alternative Specifications: Other Measures of Dental Coverage

\section{Participation}

Full $=1 \quad$ Limited=1 Emergency $=1$

1. Any Publicly Insured Patients

$\begin{array}{lcc}0.09 * * * & 0.05^{* *} & 0.05 * * * \\ (0.02) & (0.02) & (0.02) \\ 3.72 * * * & 2.59 * * * & 1.77^{* *} \\ (0.46) & (0.46) & (0.61) \\ 2.78 * * * & 1.89 * * * & 0.63 \\ (0.44) & (0.46) & (0.69)\end{array}$

Visits

2. Percent of Patients Publicly Insured

3. Percent of Gross Receipts from Government

$(0.44)$

$(0.69)$

4. Total Visits

5. Emergency/Walk-In Visits

6. Hygienist Visits

7. Visits to Publicly Insured Patients

Labor Supply, Income and Hygienist Employment

8. Hours Spent Treating Patients per Week

9. Income from Primary and Secondary Practice

10. Any Hygienist $(0,1)$

\section{Wait Time}

11. Days until Appt (Established Patient)

12. Minutes in Waiting Room (Established Patient)

$\begin{array}{lcc}3.45 * * & 0.22 & -0.74 \\ (1.44) & (1.45) & (1.55) \\ 0.70^{* * *} & 0.15 & 0.04 \\ (0.17) & (0.18) & (0.27)\end{array}$

$6.12 * *$

(1.75)

$2.91 * * *$

$(0.60)$

0.30

(2.48)

(2.07)

0.82

$(0.61)$

$\begin{array}{lcc}0.57 * * & 0.29 & 0.31 \\ (0.22) & (0.22) & (0.27) \\ 24602.67 * * * & 16411.02 * * & 12580.5 \\ (7529.92) & (7497.18) & (9836.84) \\ 0.04 * * * & 0.02 & 0.01 \\ (0.01) & (0.02) & (0.01)\end{array}$

$\begin{array}{ccc}0.73 * * & -0.01 & 0.01 \\ (0.37) & (0.38) & (0.46) \\ 0.67 * * * & 0.32 & 0.09 \\ (0.14) & (0.20) & (0.17)\end{array}$

Notes: Each row presents results from a different regression model. Column (1) reports the estimated coefficient of a variable that equals to 1 if the state offers full dental coverage for adult Medicaid beneficiaries. Column (2) reports the coefficient on a variable that equals to 1 if the state offers limited dental coverage for adult Medicaid beneficiaries. Column (3) reports the coefficient on a variable that equals 1 if the state provides only emergency dental services to Medicaid beneficiaries. All models include state and year fixed effects and practice characteristics (dentist is a general practitioner $(0,1)$, dentist owns the practice $(0,1)$, number of dentists in the practice, number of years practicing), county-level characteristics (unemployment rate, percent black, percent under 18, poverty rate) and state level characteristics (gross state product, percent uninsured). Robust standard errors are clustered by state.

$* * *$ p-value $<.01$ level; **.01<p-value $<.05 ; * .05<\mathrm{p}$-value $<.10$ 
Appendix Table 2. Coefficients on Control Variables for Select Models

\begin{tabular}{|c|c|c|c|c|c|c|}
\hline & $\begin{array}{l}\text { \% Public } \\
\text { Patients }\end{array}$ & $\begin{array}{l}\text { Total } \\
\text { Visits }\end{array}$ & $\begin{array}{l}\text { Emergency/ } \\
\text { Walk-in } \\
\text { Visits }\end{array}$ & $\begin{array}{c}\text { Hrs Spent } \\
\text { Treating } \\
\text { Patients }\end{array}$ & Income & $\begin{array}{c}\text { Any } \\
\text { Hygienist }\end{array}$ \\
\hline \multicolumn{7}{|l|}{ Control variable } \\
\hline General Practitioner & $\begin{array}{l}-1.54^{*} \\
(0.85)\end{array}$ & $\begin{array}{l}-38.76 * * * \\
(1.66)\end{array}$ & $\begin{array}{l}-0.37 * * * \\
(0.11)\end{array}$ & $\begin{array}{l}0.93 * * * \\
(0.10)\end{array}$ & $\begin{array}{l}-106677.8^{* * *} \\
(2776.3)\end{array}$ & $\begin{array}{l}0.34 * * * \\
(0.02)\end{array}$ \\
\hline Owner & $\begin{array}{c}-3.9 * * * \\
(0.64)\end{array}$ & $\begin{array}{l}13.45^{* * * *} \\
(0.97)\end{array}$ & $\begin{array}{l}0.52 * * * \\
(0.17)\end{array}$ & $\begin{array}{l}5.44 * * * \\
(0.17)\end{array}$ & $\begin{array}{l}115792.9 * * * \\
(4779.31)\end{array}$ & $\begin{array}{l}-0.08 * * * \\
(0.01)\end{array}$ \\
\hline $\begin{array}{l}\text { Number of Dentists } \\
\text { in Practice }\end{array}$ & $\begin{array}{c}0.43 * * * \\
(0.15)\end{array}$ & $\begin{array}{c}0.27 \\
(0.19)\end{array}$ & $\begin{array}{l}0.17 * * * \\
(0.06)\end{array}$ & $\begin{array}{l}0.08 * * * \\
(0.02)\end{array}$ & $\begin{array}{l}3675.15 * * * \\
(1301.3)\end{array}$ & $\begin{array}{l}0.01 * * * \\
(0.002)\end{array}$ \\
\hline Years Practicing & $\begin{array}{c}-0.10 * * * \\
(0.02)\end{array}$ & $\begin{array}{l}-0.09 * * * \\
(0.03)\end{array}$ & $\begin{array}{l}-0.05^{* * *} \\
(0.003)\end{array}$ & $\begin{array}{l}-0.12 * * * \\
(0.01)\end{array}$ & $\begin{array}{l}-638.23 * * * \\
(133.0)\end{array}$ & $\begin{array}{l}-0.001 \\
(0.001)\end{array}$ \\
\hline County Poverty Rate & $\begin{array}{c}0.68 * * * \\
(0.07)\end{array}$ & $\begin{array}{l}0.41^{* * *} \\
(0.15)\end{array}$ & $\begin{array}{l}0.09 * * * \\
(0.03)\end{array}$ & $\begin{array}{l}0.03 * * \\
(0.02)\end{array}$ & $\begin{array}{l}-185.22 \\
(477.0)\end{array}$ & $\begin{array}{l}-0.002 * \\
(0.001)\end{array}$ \\
\hline $\begin{array}{l}\text { Fraction Black in } \\
\text { County }\end{array}$ & $\begin{array}{c}-8.44 * * * \\
(0.29)\end{array}$ & $\begin{array}{l}-26.72 * * * \\
(5.85)\end{array}$ & $\begin{array}{l}-1.88^{* * *} \\
(0.61)\end{array}$ & $\begin{array}{l}-0.50 \\
(0.55)\end{array}$ & $\begin{array}{l}-16369.1 \\
(14194.3)\end{array}$ & $\begin{array}{l}-0.06 \\
(0.07)\end{array}$ \\
\hline $\begin{array}{l}\text { County } \\
\text { Unemployment Rate }\end{array}$ & $\begin{array}{c}0.01 \\
(0.11)\end{array}$ & $\begin{array}{c}0.36 \\
(0.26)\end{array}$ & $\begin{array}{l}0.09 * * * \\
(0.03)\end{array}$ & $\begin{array}{l}-0.01 \\
(0.04)\end{array}$ & $\begin{array}{l}-2254.0^{* *} \\
(1017.9)\end{array}$ & $\begin{array}{l}-0.001 \\
(0.002)\end{array}$ \\
\hline $\begin{array}{l}\text { Fraction Under } 18 \text { in } \\
\text { County }\end{array}$ & $\begin{array}{l}25.17 * * \\
(12.29)\end{array}$ & $\begin{array}{l}89.1 * * * \\
(28.26)\end{array}$ & $\begin{array}{l}9.87 * * * \\
(3.22)\end{array}$ & $\begin{array}{l}5.15^{* *} \\
(2.00)\end{array}$ & $\begin{array}{l}74329.5 \\
(72888.3)\end{array}$ & $\begin{array}{c}0.01 \\
(0.16)\end{array}$ \\
\hline $\begin{array}{l}\% \text { Uninsured in } \\
\text { State } \\
\text { Gross State Product } \\
\text { (in } \$ 100,000 \mathrm{~s} \text { ) }\end{array}$ & $\begin{array}{l}-0.30 * * * \\
(0.09) \\
-2.5 \\
(2.2)\end{array}$ & $\begin{array}{c}-0.24 \\
0.26 \\
5.4 \\
(2.8)\end{array}$ & $\begin{array}{l}-0.05 \\
(0.04) \\
0.40 \\
(0.27)\end{array}$ & $\begin{array}{l}-0.03 \\
(0.04) \\
1.22 * * \\
(0.51)\end{array}$ & $\begin{array}{l}-1535.11 \\
(950.5) \\
15342 \\
(24172)\end{array}$ & $\begin{array}{c}0.001 \\
(0.002) \\
1.02 * \\
(0.60)\end{array}$ \\
\hline
\end{tabular}

Notes: Each column presents results from a different regression model. The dependent variable is given in the first row. Independent variables are listed in the first column. All models include state and year fixed effects and an indicator variable for full dental coverage being offered to adult Medicaid beneficiaries. Full model results available for other models upon request. Robust standard errors are clustered by state.

$* * *$ p-value $<.01$ level; $* * .01<$ p-value $<.05 ; * .05<$ p-value $<.10$ 